\title{
Cardiovascular Outcomes and Proprotein Convertase Subtilisin/Kexin Type 9 Inhibitors: Current Data and Future Prospects
}

This article was published in the following Dove Press journal: Vascular Health and Risk Management

\author{
Daniel A Duprez' \\ Yehuda Handelsman (ID) ${ }^{2}$ \\ Michael Koren ${ }^{3}$ \\ 'Cardiovascular Division, School of \\ Medicine, University of Minnesota, \\ Minneapolis, MN, USA; ${ }^{2}$ Metabolic \\ Institute of America, Tarzana, CA, USA; \\ ${ }_{3}^{3}$ Jacksonville Center for Clinical \\ Research, Jacksonville, FL, USA
}

\begin{abstract}
Cardiovascular (CV) disease remains the leading cause of morbidity and mortality worldwide and poses an ongoing challenge with the aging population. Elevated lowdensity lipoprotein cholesterol (LDL-C) is an established risk factor for atherosclerotic cardiovascular disease (ASCVD), and the expert consensus is the use of statin therapy (if tolerated) as first line for LDL-C reduction. However, patients with ASCVD may experience recurrent ischemic events despite receiving maximally tolerated statin therapy, including those whose on-treatment LDL-C remains $\geq 70 \mathrm{mg} / \mathrm{dL}$, patients with familial hypercholesterolemia, high-risk subgroups with comorbidities such as diabetes mellitus, and those who have an intolerance to statin therapy. Optimal therapeutic strategies for this unmet need should deploy aggressive lipid lowering to minimize the contribution of dyslipidemia to their CV risk, particularly for very high-risk populations with additional risk factors beyond hypercholesterolemia and established ASCVD. To understand the current clinical climate and guidelines regarding ASCVD, we primarily searched PubMed for articles published in English regarding lipid-lowering therapies and CV risk reduction, including emerging therapies, and CV outcomes trials with proprotein convertase subtilisin/kexin type 9 (PCSK9) inhibitors. This review discusses the findings of recent clinical trial evidence for CV risk reduction with cholesterol-lowering therapies, with a focus on $\mathrm{CV}$ outcomes trials with PCSK9 inhibitors, and considers the impact of the study results for secondary prevention and future strategies in patients with hypercholesterolemia and CV risk despite maximally tolerated statin therapy.
\end{abstract}

Keywords: atherosclerotic cardiovascular disease, hypercholesterolemia, secondary prevention, low-density lipoprotein cholesterol, major adverse cardiovascular events

\section{Introduction}

Observed rates of cardiovascular (CV) disease morbidity and mortality in the US dropped by up to $60 \%$ between the mid-1980s and mid-2010s reflecting major advances in treatment and prevention. ${ }^{1}$ Unfortunately, this 30-year trend of lower $\mathrm{CV}$ event rates has recently plateaued. ${ }^{1}$ This significant pause in a previously favorable trend suggests the need to implement new modalities and strategies to offset the expected growing healthcare burden of CV disease in aging Western populations and in developing countries that increasingly adopt lifestyles associated with increased CV risk. ${ }^{1,2}$

Extensive data set analyses have firmly established elevated levels of lowdensity lipoprotein cholesterol (LDL-C) as a risk factor for atherosclerotic
Correspondence: Daniel A Duprez Cardiovascular Division, School of Medicine, University of Minnesota, MMC 508, Minneapolis, MN 55455, USA

$\mathrm{Tel}+\mid 6126244948$

Fax + 6126264611

Email dupre007@umn.edu
Vascular Health and Risk Management 2020:16 403-418 
cardiovascular disease (ASCVD). These evaluations include studies of epidemiologic cohorts, meta-analyses of Mendelian randomization studies, and clinical trials. Randomized interventional treatment studies have clearly demonstrated a consistent dose-dependent log-linear association between the degree of LDL-C lowering and reduction of ASCVD risk. $^{3}$

Guideline committees and experts almost uniformly recommend LDL-C lowering with 3-hydroxy-3-methylglutaryl coenzyme A reductase inhibitors (statins) as firstline treatment for $\mathrm{CV}$ risk reduction in patients who cannot control LDL-C levels with diet and exercise. ${ }^{4-6}$ The Cholesterol Treatment Trialists' Collaboration (CTTC) meta-analyses of large, randomized, controlled statin trials - including studies of statin versus placebo and more versus less intensive statin therapy - provide conclusive evidence for $\mathrm{CV}$ risk reduction with statin treatment, irrespective of age. ${ }^{7}$ CTTC calculated a $21 \%$ decrease in the 5-year incidence of major vascular events per $1 \mathrm{mmol} / \mathrm{L}(39 \mathrm{mg} / \mathrm{dL})$ reduction in LDL-C; more versus less intensive statin therapy provided a $24 \% \mathrm{CV}$ benefit. $^{7}$

\section{Limits of Statin Therapy}

Despite robust analyses and unequivocal benefits, questions remain about the optimal statin strategy in selected populations. For example, some clinicians have raised concerns about the use of statins in older patients, as many studies in the CTTC data set did not include patients aged $>75$ years. $^{7}$ Populations that poorly tolerate statins also challenge clinicians. These populations include patients of Asian descent who may not tolerate high doses of statins and those with a history of adverse effects while taking statins. ${ }^{8}$

Statin therapy has proven limitations of effectiveness. ${ }^{9-11}$ Many patients taking statins do not achieve the optimal LDL-C levels of $<70 \mathrm{mg} / \mathrm{dL}(1.8 \mathrm{mmol} / \mathrm{L})$ or $55 \mathrm{mg} / \mathrm{dL}(1.4 \mathrm{mmol} / \mathrm{L})$ currently recommended by consensus statements. Other patients experience recurrent ischemic events even while receiving maximally tolerated statin therapy. ${ }^{9,10}$ Patients with intolerance to statin therapy, most commonly presenting as muscle-related symptoms, may interrupt or discontinue treatment. ${ }^{12-14}$ Further, statin use has been associated with a risk of new-onset diabetes. ${ }^{15-17}$

Lipid treatment therapies added on to statins offer the possibility of providing further $\mathrm{CV}$ event reductions that might contribute to resuming the positive trend in epidemiological CV risk. Ezetimibe, an inhibitor of cholesterol absorption, when added to statin therapy, as shown in the large Improved Reduction of Outcomes: Vytorin Efficacy International Trial (IMPROVE-IT), reduced subsequent $\mathrm{CV}$ events in patients following an acute coronary syndrome (ACS). ${ }^{18}$ In this trial, modest changes in LDL-C attributable to ezetimibe $(15.8 \mathrm{mg} / \mathrm{dL}$ or $0.4 \mathrm{mmol} / \mathrm{L}$ reduction) led to a $6 \%$ reduction of $\mathrm{CV}$ events over 7 years. Although this result supports the LDL-C treatment hypothesis that "lower is better," it also led to the understanding of the limited benefit of small incremental LDL-C lowering beyond statins. Other add-on therapies to statins have not improved outcomes. For example, trials adding fibrates and niacin to statins showed very small effects on LDL-C and no clinical outcomes benefit. ${ }^{19,20}$ In sum, these studies suggested the need for new agents that have far greater LDL-C lowering effects.

Most recently, therapies directed against proprotein convertase subtilisin/kexin type 9 (PCSK9) have shown the achievement of large incremental reductions of LDL-C and other favorable lipid effects in addition to those attributable to statins. The availability of these novel agents allows clinicians to help lower serum LDL-C to previously unattainable levels. Below, we report an extensive review of the literature to study and summarize the impact of this new class of anti-hyperlipidemia agents and speculate on future advances.

\section{Literature Review}

We identified the clinical studies and cholesterol management guidelines discussed in this review through searches of PubMed for articles published in English. We searched for lipid-lowering therapies and CV risk reduction, including emerging therapies, with a focus on CV outcomes trials (CVOTs) using PCSK9 inhibitors with the query terms "proprotein convertase subtilisin/ kexin type 9", "PCSK9", "alirocumab", "evolocumab", or "inclisiran", up to December 2019 with no lower limit on dates. Additional articles were added from searches of "clinicaltrials.gov" and abstracts presented at major cardiology conferences. This article provides an overview of the efficacy and safety of PCSK9 inhibitors for $\mathrm{CV}$ risk reduction, with a focus on CVOTs, including data in high-risk patient subgroups, and considers the clinical impact of the study results for secondary prevention strategies in patients with hypercholesterolemia and CV risk despite maximally tolerated statin therapy. 


\section{PCSK9 - A New Target for Cardiovascular Risk Reduction}

The discovery of the serine protease PCSK9 in $2003^{21}$ provided a novel potential target for treating hypercholesterolemia. In the same year, gain-of-function mutations in the gene for PCSK9 were linked with autosomal dominant hypercholesterolemia, and in 2005 loss-of-function mutations were identified in individuals with low levels of LDL-C and reduced risk of coronary heart disease, suggesting that PCSK9 plays a role in the regulation of LDL-C. In a longitudinal study in a large population, sequence variations in PCSK9 were associated with lower plasma levels of LDL-C, ie lifelong reduction in LDL-C, and provided protection against coronary heart disease. ${ }^{22}$ Mechanistic studies established that PCSK9 is a circulating protein that binds to LDL receptors on hepatocytes and targets these receptors for lysosomal degradation. ${ }^{23}$ PCSK9 raises LDL-C levels by preventing normal LDL receptor recycling to the cell membrane.

Monoclonal antibodies (mAbs) targeted against PCSK9 bind to the molecule and subsequently prevent it from forming a complex with the LDL receptor. ${ }^{24}$ This mechanism effectively improves LDL-C clearance as the number of available LDL receptors on hepatocytes is increased. Two mAb PCSK9 inhibitors (alirocumab and evolocumab) have received marketing approval. Other mAbs against PCSK9 underwent clinical testing but failed to progress to the medical marketplace. RG7652 (Roche) and LY3015014 (Eli Lilly) did not undergo phase 3 trials based on manufacturers' decisions. Bococizumab completed a phase 2 trial $^{25}$ and was entered for evaluation in two parallel CVOT trials (SPIRE-1 and -2$)^{26}$ in 27,438 patients at high CV risk. These studies were discontinued early, following findings that showed attenuated LDL-C lowering with bococizumab over time related to the development of antidrug antibodies. ${ }^{26}$ Unlike alirocumab and evolocumab, both fully human mAbs with low immunogenicity, bococizumab is a humanized $\mathrm{mAb}$ retaining $\sim 3 \%$ of a murine sequence in its antigen-binding complementarity-determining region. This difference probably affected its immunogenicity profile compared with the approved products. ${ }^{26}$ Development of bococizumab has ceased.

\section{Monoclonal Antibody PCSK9 Inhibitors - Early Trials}

Initial trials with alirocumab and evolocumab on background statin therapy demonstrated large reductions in LDL-C (by $\sim 50 \%-60 \%),{ }^{27-31}$ and by $\sim 47 \%-51 \%$ as monotherapy. ${ }^{32,33}$ In phase 3 clinical trials, alirocumab and evolocumab demonstrated significant reductions in LDL-C levels in individuals at high risk for $\mathrm{CV}$ events and/or with heterozygous familial hypercholesterolemia on background statin therapy ${ }^{34-42}$ regardless of age, ${ }^{43,44}$ as monotherapy, ${ }^{33,45}$ and in patients with statin intolerance. ${ }^{40,46}$ Although it was expected that PCSK9 inhibitors would be used on top of statins, the monotherapy trials suggested utility when statin therapy could not be used. These impressive lipid results in early studies suggested that further CV risk reduction could be achieved if the relationship between lower LDL-C levels and CV risk, that was observed by the CTTC and Improved Reduction of Outcomes: Vytorin Efficacy International Trial investigators, was continuous down to lower LDL-C levels.

Importantly, the favorable lipid effects of alirocumab and evolocumab included patients studied in high CV risk subgroups. These studies involved patients with diabetes, ${ }^{47-50}$ mixed dyslipidemia, ${ }^{51-53}$ chronic kidney disease,${ }^{54,55}$ and established ASCVD, ${ }^{56,57}$ including high-risk subgroups with prior percutaneous coronary intervention/coronary artery bypass grafting $(\mathrm{CABG})^{58}$ or type 2 diabetes mellitus. ${ }^{59}$ Post hoc analyses of 52-week evolocumab (OSLER) and 78-week alirocumab (LONG TERM) pivotal studies indicated statistically significant relative risk reductions (RRRs) of $48 \%-53 \%$ in $\mathrm{CV}$ events versus placebo, increasing the interest in dedicated CVOTs for these mAbs. ${ }^{60,61}$

\section{PCSK9 Inhibitor Cardiovascular Outcomes Trials}

Trial design summaries of the completed large dedicated CVOTs are presented in Table $1,{ }^{61,62}$ for evolocumab (FOURIER; $^{63}$ in 27,564 patients with established ASCVD [myocardial infarction (MI)/stroke/peripheral arterial disease (PAD)] at 1242 sites in 49 countries) and alirocumab (ODYSSEY OUTCOMES; ${ }^{62}$ in 18,924 highrisk patients between 1 and 12 months post ACS at 1315 sites in 57 countries). Table 1 includes a description of the primary 4-point (in ODYSSEY OUTCOMES) and 5-point (in FOURIER) composite endpoints of major cardiovascular events (MACE) of each trial.

\section{FOURIER}

The FOURIER trial evaluated evolocumab $140 \mathrm{mg}$ every 2 weeks (Q2W) or $420 \mathrm{mg}$ every 4 weeks in patients (mean age 63 years, 75\% men) with ASCVD and elevated 
Table I Prospective Phase 3 Cardiovascular Outcomes Trials

\begin{tabular}{|c|c|c|c|}
\hline & FOURIER ${ }^{61}$ & ODYSSEY OUTCOMES ${ }^{62}$ & ORION-4 (NCT03705234) \\
\hline IMP & Evolocumab & Alirocumab & Inclisiran \\
\hline Patients, $\mathrm{n}$ & $\begin{array}{l}27,564 \text { (prior ASCVD: } \mathrm{Ml} \text {, non-hemorrhagic stroke, } \\
\text { PAD, and } \geq 1 \text { major } / 2 \text { minor additional risk factors) }\end{array}$ & I8,924 (ACS in previous I-12 months) & $\begin{array}{l}\text { 15,000 planned (elevated LDL-C } \\
\text { and ASCVD) }\end{array}$ \\
\hline Trial design & $r, d b, p c$ & $\mathrm{r}, \mathrm{db}, \mathrm{pc}$ & $r, d b, p c$ \\
\hline Trial status & Completed & Completed & Ongoing \\
\hline Dosing regimen & $140 \mathrm{mg}$ Q2W or $420 \mathrm{mg}$ Q4W & $75^{\mathrm{a} / \mathrm{I}} 50 \mathrm{mg} \mathrm{Q} 2 \mathrm{~W}$ & $\begin{array}{l}300 \mathrm{mg} \mathrm{SC} \text { injection at } 3 \text { months, } \\
\text { then every } 6 \text { months }\end{array}$ \\
\hline Inclusion criteria & $\begin{array}{l}\mathrm{LDL}-\mathrm{C} \geq 70 \mathrm{mg} / \mathrm{dL} \text { or non-HDL-C } \geq 100 \mathrm{mg} / \mathrm{dL} \text { on } \\
\text { background high-intensity statin following at least } \\
\text { atorvastatin } 20 \mathrm{mg} / \text { day or its equivalent, with/ } \\
\text { without ezetimibe }\end{array}$ & $\begin{array}{l}\mathrm{LDL}-\mathrm{C} \geq 70 \mathrm{mg} / \mathrm{dL} \text {, non- } \mathrm{HDL}-\mathrm{C} \geq 100 \mathrm{mg} / \mathrm{dL} \text {, or apoB } \\
\geq 80 \mathrm{mg} \text {; on background atorvastatin } 40-80 \text { or } \\
\text { rosuvastatin } 20-40 \mathrm{mg} / \text { day, or maximum tolerated } \\
\text { dose, age } \geq 40 \text { years }\end{array}$ & $\begin{array}{l}\text { Age } \geq 55 \text { years; history of } \mathrm{MI} / \mathrm{IS} / \\
\text { PAD }\end{array}$ \\
\hline $\begin{array}{l}\text { High-intensity } \\
\text { statins }\end{array}$ & $\begin{array}{l}69 \% \text { (atorvastatin } \geq 40 \mathrm{mg} \text {, rosuvastatin } \geq 20 \mathrm{mg} \text {, or } \\
\text { simvastatin } 80 \mathrm{mg} \text { ) }\end{array}$ & $89 \%$ (evidence-based statin dose) & \\
\hline Median follow-up & 2.2 years & 2.8 ( $44 \%$ with $\geq 3$ years) & 5 years \\
\hline Endpoints & $\begin{array}{l}\text { Primary: CV death, Ml, stroke, revascularization, or } \\
\text { hospitalization for UA } \\
\text { Secondary: CV death, MI/stroke }\end{array}$ & $\begin{array}{l}\text { Primary: CHD death, MI, IS, or hospitalization for UA } \\
\text { Secondary: CHD (any or major) or CV event; } \\
\text { composite of death from any cause/nonfatal MI/ } \\
\text { stroke; death from CHD, CV, or any cause }\end{array}$ & $\begin{array}{l}\text { Primary: Time to first } \\
\text { occurrence of CHD death/MI/ } \\
\text { fatal or non-fatal IS/urgent } \\
\text { coronary revascularization }\end{array}$ \\
\hline
\end{tabular}

Note: ${ }^{a} 7.7 \%$ blindly switched to placebo at median 8.3 months after 2 consecutive LDL-C measurements of $<15 \mathrm{mg} / \mathrm{dL}$ on the $75 \mathrm{mg}$ dose.

Abbreviations: apoB, apolipoprotein B; ASCVD, atherosclerotic cardiovascular disease; db, double-blind; CHD, coronary heart disease; CV, cardiovascular; FOURIER, Further Cardiovascular Outcomes Research with PCSK9 Inhibition in Subjects with Elevated Risk; IMP, investigational medicinal product; IS, ischemic stroke; LDL-C, lowdensity lipoprotein cholesterol; MI, myocardial infarction; non-HDL-C, non-high-density lipoprotein cholesterol; ODYSSEY OUTCOMES, Evaluation of Cardiovascular Outcomes After an Acute Coronary Syndrome During Treatment With Alirocumab; PAD, peripheral artery disease; pc, placebo-controlled; PCSK9, proprotein convertase subtilisin/kexin type 9; Q2W, every 2 weeks; Q4W, every 4 weeks; r, randomized; SPIRE, Studies of PCSK9 Inhibition and the Reduction of Vascular Events; SC, subcutaneous; UA, unstable angina.

LDL-C levels ( $\geq 70 \mathrm{mg} / \mathrm{dL})$ despite statin therapy, including $69 \%$ on high-intensity statin therapy (Table 1). Evolocumab led to consistent and sustained reductions in LDL-C and other atherogenic lipids. ${ }^{63}$ Compared with placebo, mean reduction from baseline in LDL-C with evolocumab was $59 \%$ at 11 months; at median follow-up of 2.2 years, fewer MACE had occurred with evolocumab than placebo ( $9.8 \%$ vs $11.3 \%$; hazard ratio [HR], 0.85 ; $\mathrm{p}<0.001$, Figure $1 \mathrm{~A}$ ). In addition to the $15 \%$ reduction in the risk of MACE, there was a $20 \%$ reduction in the risk of the main secondary efficacy endpoint, composite of $\mathrm{CV}$ death/MI/ischemic stroke $(\mathrm{p}<0.001)$, and reductions in other secondary endpoints. ${ }^{63}$

PCSK9 inhibitors have been shown to significantly reduce plasma lipoprotein(a) [Lp(a)] levels; ${ }^{64,65}$ however, the relationship between Lp(a) levels, PCSK9 inhibition, and $\mathrm{CV}$ risk reduction is not clear. ${ }^{66}$ In a prespecified analysis of FOURIER that assessed Lp(a) levels up to 48-weeks of treatment, in the placebo group, patients with higher baseline $\mathrm{Lp}$ (a) had a higher risk of coronary heart disease death, MI, or urgent revascularization (adjusted HR quartile 4: quartile 1, 1.22), independent of LDL-C. ${ }^{67}$ Evolocumab significantly reduced $\mathrm{Lp}$ (a) from baseline to 48 weeks by a median of $27 \%$ with a moderate correlation between the percent change in Lp(a) and LDL-C $(\mathrm{p}<0.001)$. In patients with higher $(>$ median) than lower ( $\leq$ median) baseline Lp(a), the reduction in the risk of MACE was greater, 23\% (HR 0.77) and 7\% (HR 0.93), respectively.

\section{FOURIER - Subanalyses in High-Risk Patients}

In pre-specified secondary analyses of FOURIER, evolocumab led to significantly reduced events on background statin therapy (Figure 1B). ${ }^{68}$ Consistent significant reductions in the primary $\mathrm{CV}$ endpoint were shown in high-risk subgroups including baseline $\mathrm{PAD}^{69}$ or diabetes. ${ }^{70}$ The higher-risk PAD patients had larger absolute risk reductions (ARRs) for primary and the key secondary endpoints. Lowering LDL-C, even down to $<10 \mathrm{mg} / \mathrm{dL}$, reduced the risk of major adverse limb events. LDL-C 
A

\begin{tabular}{|c|c|c|c|c|c|}
\hline $\begin{array}{c}\text { CV outcomes at } 2.2 \text { years } \\
\text { follow-up, } n(\%)\end{array}$ & $\begin{array}{c}\text { Evolocumab } \\
(n=13,784)\end{array}$ & $\begin{array}{l}\text { Placebo } \\
(n=13,780)\end{array}$ & & $\begin{array}{c}\text { HR } \\
\text { (95\% Cl; p-value) }\end{array}$ & RRR \\
\hline Primary endpoint ${ }^{\mathrm{a}}$ & $1344(9.8)$ & $1563(11.3)$ & $\mapsto$ & $0.85(0.79-0.92 ; p<0.001)$ & $15 \%$ \\
\hline Key secondary endpoint ${ }^{b}$ & $816(5.9)$ & $1013(7.4)$ & $\mapsto$ & $0.80(0.73-0.88 ; p<0.001)$ & $20 \%$ \\
\hline \multicolumn{6}{|l|}{ Other secondary endpoints ${ }^{c}$} \\
\hline CV death & $251(1.8)$ & $240(1.7)$ & $\longmapsto$ & $1.05(0.88-1.25 ; p=0.62)$ & \\
\hline Death from any cause & $444(3.2)$ & $426(3.1)$ & & $1.04(0.91-1.19 ; p=0.54)$ & \\
\hline MI & $468(3.4)$ & $639(4.6)$ & $\mapsto$ & $0.73(0.65-0.82 ; p<0.001)$ & $27 \%$ \\
\hline Stroke & $207(1.5)$ & $262(1.9)$ & $\longmapsto$ & $0.79(0.66-0.95 ; p=0.01)$ & $21 \%$ \\
\hline \multirow[t]{2}{*}{$\begin{array}{l}\text { Coronary } \\
\text { revascularization }\end{array}$} & $759(5.5)$ & $965(7.0)$ & $\mapsto$ & $0.78(0.71-0.86 ; p<0.001)$ & $22 \%$ \\
\hline & \multicolumn{5}{|c|}{5} \\
\hline
\end{tabular}

B

\begin{tabular}{|c|c|c|c|c|c|c|c|}
\hline $\begin{array}{l}\text { CV outcomes at } 2.2 \text { years } \\
\text { follow-up, } n(\%)\end{array}$ & $\begin{array}{c}\text { Evolocumab } \\
(n=13,784)\end{array}$ & $\begin{array}{l}\text { Placebo } \\
(n=13,780)\end{array}$ & i & $\begin{array}{c}\text { HR } \\
(95 \% \mathrm{Cl} ; \mathrm{p} \text {-value })\end{array}$ & RRR & ARR & NNT \\
\hline Total CV events ${ }^{a, d}$ & 2192 & 2714 & $\mapsto$ & $0.82(0.75-0.90 ; p<0.001)$ & $18 \%$ & & \\
\hline Recurrent events ${ }^{a}$ & 848 & 1151 & $\longmapsto$ & $0.74(0.65-0.85)$ & $26 \%$ & & \\
\hline Total MI & & & $\longmapsto$ & $0.74(0.65-0.84 ; p<0.001)$ & $26 \%$ & & \\
\hline Strokes & & & $\longmapsto$ & $0.77(0.64-0.93 ; p=0.007)$ & $23 \%$ & & \\
\hline Coronary revascularization & & & $\mapsto$ & $0.78(0.71-0.87 ; p<0.001)$ & $22 \%$ & & \\
\hline \multicolumn{8}{|l|}{ Subgroup analyses ${ }^{a}$} \\
\hline \multicolumn{8}{|l|}{ PAD } \\
\hline With $(n=3642)$ & 13.3 & 16.8 & $\longmapsto$ & $0.79(0.66-0.94 ; p=0.0098)$ & $21 \%$ & $3.5 \%$ & 29 \\
\hline Without $(n=23,922)$ & 10.5 & 12.1 & $\mapsto \rightarrow$ & $0.86(0.80-0.93 ; p<0.001)$ & $14 \%$ & $1.6 \%$ & 63 \\
\hline \multicolumn{8}{|l|}{$D M^{f}$} \\
\hline With $(n=11,031)$ & $622 / 5515(14.4)$ & $739 / 5516(17.1)$ & $\rightsquigarrow$ & $0.83(0.75-0.93 ; p=0.008)$ & $17 \%$ & $2.7 \%$ & 37 \\
\hline \multirow[t]{2}{*}{ Without $(n=16,533)$} & $722 / 8270(11.4)$ & $824 / 8264(13.0)$ & $\mapsto$ & $0.87(0.79-0.96 ; p=0.0052)$ & $13 \%$ & $1.6 \%$ & 63 \\
\hline & & 0.5 & २ $\left(95^{\circ}\right.$ & & & & \\
\hline
\end{tabular}

Figure I FOURIER. ${ }^{63}$ (A) primary and secondary endpoints and (B) secondary analyses in high-risk subgroups. ${ }^{\text {a }} \mathrm{CV}$ death, MI/stroke, hospitalization for UA or coronary revascularization; ARR and RRR are indicated when reported in the reference, and NNT values were calculated as I/ARR. ${ }^{b} \mathrm{CV}$ death, MI/stroke. ${ }^{\mathrm{C} D u e}$ to the hierarchical nature of the statistical testing, the $P$ values for 'Other secondary endpoints' are considered exploratory. 'Incidence RR reported from negative binomial regression model as $\operatorname{RR}(95 \% \mathrm{Cl})^{68}$ e 2.5 -year Kaplan-Meier rate ${ }^{69} \mathrm{f}$ Number of patients (3-year Kaplan-Meier rate). ${ }^{70}$

Abbreviations: ARR, absolute risk reduction; Cl, confidence interval; CV, cardiovascular; DM, diabetes mellitus; HR, hazard ratio; MI, myocardial infarction; NNT, number needed to treat; PAD, peripheral arterial disease; RR, rate ratio; RRR, relative risk reduction; UA, unstable angina.

reductions with evolocumab were similar in patients with $(57 \%)$ and without $(60 \%)$ diabetes $(\mathrm{p}<0.0001$ for both); both groups achieved LDL-C levels of $31 \mathrm{mg} / \mathrm{dL}$ at 48 weeks. As shown for patients with $\mathrm{PAD},{ }^{69}$ ARRs for the primary endpoint were greater for patients with than without baseline diabetes, reflecting the higher risk among diabetics, ${ }^{70}$ and consequent number needed to treat (NNT) values were lower for patients with than without PAD (29 vs 63) or diabetes (37 vs 63).

Additionally, an analysis of high-risk patients with prior MI in FOURIER showed that those at increasing risk, ie closer to their most recent MI, with multiple prior MIs, or with residual multivessel coronary artery disease, experienced greater risk reductions with LDL-C lowering: $20 \%, 18 \%$, and $21 \%$, respectively. ${ }^{71}$ By contrast,
RRRs were $5 \%, 8 \%$, and $7 \%$, respectively, in those without MI.

\section{ODYSSEY OUTCOMES}

The effect of alirocumab on the risk of MACE was evaluated over a median of 2.8 years in ODYSSEY OUTCOMES in high-risk patients with a recent ACS and elevated levels of atherogenic lipoproteins despite statin therapy at a high intensity ( $89 \%$ of patients) or maximum tolerated dose. ${ }^{62}$ The minimum follow-up was 2 years, with many patients $(44 \%)$ treated for $\geq 3$ years. In this CVOT, alirocumab was blindly titrated to target an LDL-C of $25-50 \mathrm{mg} / \mathrm{dL}$ using 2 dosing strategies (75 mg and $150 \mathrm{mg}$ Q2W); patients were initiated on alirocumab $75 \mathrm{mg}$ Q2W and switched to $150 \mathrm{mg}$ Q2W if their LDL-C levels remained above $50 \mathrm{mg} / \mathrm{dL}(\mathrm{n}=2615)$, but 
were titrated to $75 \mathrm{mg}$ if their LDL-C fell below $25 \mathrm{mg} / \mathrm{dL}$ $(\mathrm{n}=805)$; patients with 2 consecutive LDL-C measurements $<15 \mathrm{mg} / \mathrm{dL}$ while on the $75 \mathrm{mg}$ dose $(\mathrm{n}=730)$ were blindly switched to placebo for the remainder of the trial. Consistent and sustained reductions in LDL-C and other atherogenic lipids were observed. By 12 months, compared with placebo, LDL-C reduction from baseline with alirocumab was $61.0 \%$ in an on-treatment analysis, and the composite primary $\mathrm{CV}$ endpoint occurred in fewer alirocumab than placebo recipients $(9.5 \%$ vs $11.1 \%$; HR, $0.85 ; \mathrm{p}<0.001) .{ }^{62}$ Further details of the effect of alirocumab on primary and secondary endpoints are presented in Figure 2A.
Fewer deaths from any cause were observed with alirocumab over median 2.8 years of follow-up (Figure 2B); however, hierarchical analyses testing showed no significant difference in death from coronary artery disease; hence, the observed mortality benefit with alirocumab is considered an exploratory/hypothesis-generating finding. ${ }^{72}$ A mortality benefit was also seen in prespecified secondary analyses of patients who were followed for $\geq 3$ years and in those with LDL-C $\geq 100 \mathrm{mg} /$ $\mathrm{dL}$ at baseline. ${ }^{62,73}$ In a further analysis, the number of recurrent nonfatal $\mathrm{CV}$ events and all-cause mortality was reduced over a median of 2.8 years of follow-up, which was almost twice the number of first events prevented. ${ }^{74}$

\begin{tabular}{|c|c|c|c|c|c|c|}
\hline $\begin{array}{l}\text { CV outcomes at } 2.8 \text { years } \\
\text { follow-up, } n(\%)\end{array}$ & $\begin{array}{c}\text { Alirocumab } \\
\text { ( } \mathrm{n}=9642)\end{array}$ & $\begin{array}{l}\text { Placebo } \\
(n=9462)\end{array}$ & & $\begin{array}{c}\text { HR } \\
\text { (95\% Cl; p-value) }\end{array}$ & RRR & ARR \\
\hline Primary endpoint ${ }^{a}$ & $903(9.5)$ & $1052(11.1)$ & $\rightarrow$ & $0.85(0.78-0.93 ; p<0.001)$ & $15 \%$ & $1.6 \%$ \\
\hline \multicolumn{7}{|l|}{ Major secondary endpoints } \\
\hline Any $\mathrm{CHD}$ event & $1199(12.7)$ & $1349(14.3)$ & $\rightarrow$ & $0.88(0.81-0.95 ; p=0.001)$ & $12 \%$ & \\
\hline Major CHD event & $793(8.4)$ & $899(9.5)$ & $\mapsto$ & $0.88(0.80-0.96 ; p=0.006)$ & $12 \%$ & \\
\hline Any $\mathrm{CV}$ event & $1301(13.7)$ & $1474(15.6)$ & $\rightarrow \infty$ & $0.87(0.81-0.94 ; p<0.001)$ & $13 \%$ & \\
\hline $\begin{array}{l}\text { Composite of death from any } \\
\text { cause, nonfatal Ml/stroke }\end{array}$ & $973(10.3)$ & $1126(11.9)$ & $\rightarrow$ & $0.86(0.79-0.93 ; p<0.001)$ & $14 \%$ & \\
\hline Death from CHD & $205(2.2)$ & $222(2.3)$ & $\longmapsto$ & $0.92(0.76-1.11 ; p=0.38)$ & $8 \%$ & \\
\hline Death from $\mathrm{CV}$ causes & $240(2.5)$ & $271(2.9)$ & $\longmapsto$ & $0.88(0.74-1.05)$ & $12 \%$ & \\
\hline \multirow[t]{2}{*}{ Death from any cause } & $334(3.5)$ & $392(4.1)$ & $\longmapsto$ & $0.85(0.73-0.98)$ & $15 \%$ & \\
\hline & & 0.5 & HR & & & \\
\hline
\end{tabular}

\begin{tabular}{|c|c|c|c|c|c|c|c|}
\hline $\begin{array}{l}\text { CV outcomes at } 2.8 \text { years } \\
\text { follow-up, } n(\%)\end{array}$ & $\begin{array}{c}\begin{array}{c}\text { Alirocumab } \\
(\mathrm{n}=9462)\end{array}\end{array}$ & $\begin{array}{l}\text { Placebo } \\
(\mathrm{n}=9462)\end{array}$ & & $\begin{array}{c}\text { HR } \\
\text { (95\% Cl; p-value) }\end{array}$ & RRR & ARR & NNT \\
\hline Total mortality ${ }^{\mathrm{b}}$ & $334(3.5)$ & $392(4.1)$ & $\longmapsto$ & $0.85(0.73-0.98 ;$ nominal $p=0.03)$ & $15 \%$ & & \\
\hline CV deaths & $240(2.5)$ & $271(2.9)$ & $\longmapsto$ & $0.88(0.74-1.05 ; p=0.15)$ & $12 \%$ & & \\
\hline Non-CV deaths & $94(1.0)$ & $121(1.3)$ & $\longrightarrow$ & $0.77(0.59-1.01 ; p=0.06)$ & $23 \%$ & & \\
\hline $\begin{array}{l}\text { Total mortality over } \geq 3 \text { years } \\
(n=8242) \\
\text { Polyvasculardisease }\end{array}$ & $94(1.0)$ & $121(1.3)$ & $\longmapsto$ & $0.78(0.65-0.94 ; p=0.01)$ & $22 \%$ & & \\
\hline Monovascular (91.8\%) & $8.5 \%$ & $10.0 \%$ & $\mapsto$ & $0.85(0.77-0.93 ; p=0.0008)$ & & $1.4 \%$ & 71 \\
\hline Polyvascular (2 beds; $7.4 \%$ ) & $20.1 \%$ & $22.2 \%$ & & & & $1.9 \%$ & 53 \\
\hline Polyvascular ( 3 beds; $0.8 \%$ ) & $26.8 \%$ & $39.7 \%$ & & $0.64(0.35-1.12 ; p=0.11)$ & & $13 \%$ & 8 \\
\hline \multicolumn{8}{|l|}{$\mathrm{DM}^{\mathrm{a}}$} \\
\hline Normoglycemia (27.7\%) & $7.3 \%$ & $8.5 \%$ & $\longrightarrow$ & $0.85(0.70-1.03)$ & $15 \%$ & $1.2 \%$ & 83 \\
\hline Prediabetes $(43.6 \%)$ & $8.0 \%$ & $9.2 \%$ & $\longmapsto$ & $0.86(0.74-1.00)$ & $14 \%$ & $1.2 \%$ & 83 \\
\hline $\mathrm{DM}(28.8 \%)$ & $14.1 \%$ & $16.4 \%$ & $\longmapsto$ & $0.84(0.74-0.97)$ & $16 \%$ & $2.3 \%$ & 43 \\
\hline \multicolumn{8}{|l|}{ Age $^{a}$} \\
\hline$<65(73 \%)$ & $8.8 \%$ & $9.7 \%$ & $\mapsto$ & $0.89(0.80-1.00)$ & $11 \%$ & $0.9 \%$ & 111 \\
\hline \multirow[t]{2}{*}{$\geq 65(27 \%)$} & $12.9 \%$ & $16.8 \%$ & $\longmapsto$ & $0.78(0.68-0.91)$ & $22 \%$ & $3.9 \%$ & 26 \\
\hline & & & HR ( & $6 \mathrm{Cl})$ & $\frac{5}{5}$ & & \\
\hline
\end{tabular}

Figure 2 ODYSSEY OUTCOMES (A) primary and key secondary endpoints, ${ }^{62}$ and (B) secondary analyses in high-risk subgroups. ${ }^{73,77-79}$ a $\mathrm{CHD}$ death, nonfatal MI, ischemic stroke, or hospitalization for unstable angina; ARR and RRR are indicated when reported in the reference, and NNT values were calculated as I/ARR. ${ }^{\mathrm{b}}$ Monovascular disease (coronary); 2 beds (coronary and peripheral artery or cerebrovascular); 3 vascular beds (coronary, peripheral artery, cerebrovascular).

Abbreviations: ARR, absolute risk reduction; CHD, coronary heart disease; $\mathrm{Cl}$, confidence interval; CV, cardiovascular; HR, hazard ratio; MI, myocardial infarction; NNT, number needed to treat; RRR, relative risk reduction; UA, unstable angina. 
In a pre-specified analysis of ODYSSEY OUTCOMES, alirocumab was associated with an $\sim 23 \%$ reduction in $\mathrm{Lp}(\mathrm{a})$, and the absolute reduction was directly related to the baseline level. ${ }^{75}$ Additionally, alirocumab reduced LDL-C [corrected for the cholesterol content in $\mathrm{Lp}(\mathrm{a})]$ and the risk of MACE (HR, 0.85). Following adjustment for baseline concentrations of Lp(a) and LDL-C, and demographic and clinical characteristics, the reductions in $L p(a)$ predicted lower risk of MACE after ACS independent of the concurrent reduction in LDL-C. ${ }^{75}$ The Lp(a) results from FOURIER in patients with $\mathrm{ASCVD}^{67}$ and these results from ODYSSEY OUTCOMES $^{75}$ in patients with recent ACS support the suggestion that patients with higher baseline Lp(a) levels derive greater relative and absolute $L p(a)$ reductions, and hence greater coronary benefit from PCSK9 inhibition. ${ }^{66}$

\section{ODYSSEY OUTCOMES - Subanalyses in High-Risk Patients}

In prespecified subanalyses, higher-risk patients derived larger ARRs for MACE and mortality with alirocumab and lower NNT values (Figure 2B) ${ }^{76}$ These populations included patients with more recent ACS, baseline polyvascular disease $^{77}$ or prior CABG. ${ }^{76}$ Higher disease severity, ie, increased number of diseased vascular beds or timing of CABG, led to larger ARRs for MACE and mortality with treatment (Figure 2B).$^{76}$ Analysis of further LDL-C lowering with alirocumab on CV outcomes by baseline glycemic status (normoglycemia, prediabetes, or diabetes) showed an $\sim 2$-fold ARR in patients with diabetes compared with those without (Figure 2B; Pinteraction $=0.0019$ ) ${ }^{78}$ In an analysis that compared the effect of alirocumab versus placebo according to age, alirocumab improved outcomes for patients with recent ACS irrespective of age, $\geq 65$ versus $<65$ years, and even in older patients (aged $\geq 75$ years), there was increased absolute benefit without harm (Figure 2B). ${ }^{79}$

Initially, after approval, concerns were raised about the expense and value of the novel PCSK9 antibody class that may have contributed to underutilization in clinical practice. ${ }^{80,81}$ Notably, the acquisition costs of PCSK9 inhibitors have decreased over time, and identification of patient groups that may derive the greatest clinical benefit ${ }^{82}$ have improved access. A prespecified analysis of ODYSSEY OUTCOMES showed that, compared with placebo, alirocumab significantly reduced total (first and subsequent) hospitalizations and death, and increased days alive and out of hospital, ${ }^{83}$ demonstrating that the clinical benefit translates to a reduction in the personal and overall healthcare burden of the disease. These results were further demonstrated with the cost-effectiveness of alirocumab shown using data from ODYSSEY OUTCOMES. ${ }^{84}$

\section{Safety Data - Long-Term Safety}

Open-label, uncontrolled long-term extensions of phase 3 clinical trials evaluating the efficacy and safety of alirocumab up to 3 years (ODYSSEY OLE) ${ }^{85}$ and evolocumab up to 5 years (OSLER-1, OSLER-2) ${ }^{86-88}$ indicate that this class of lipid-lowering therapy is generally well tolerated and results in consistent, sustained reductions in LDL-C. Overall incidence rates of treatment-emergent adverse events were similar or lower than that seen in the parent studies in which rates tended to be similar between treatment and placebo. ${ }^{85,88}$ Adverse event rates for injectionsite reactions dropped with continued use of evolocumab, and rates of new-onset diabetes or neurocognitive events did not increase with long-term use. ${ }^{88}$

In a post hoc analysis of data from 10 alirocumab phase 3 trials, the association between lower LDL-C levels and reduced CV risk extended to levels below $50 \mathrm{mg} / \mathrm{dL} .{ }^{89}$ Despite safety concerns about reducing LDL-C to very low levels, no data set has found increased serious morbidity or mortality associated with the therapeutic lowering of LDL-C to date, including patients with levels reduced to $<25 \mathrm{mg} / \mathrm{dL} .{ }^{88,90}$ Although the PCSK9 trials with safety data over 3-5 years showed sustained LDL-C reductions and no additional safety concerns beyond those observed in the shorter-term parent trials, the long-term safety of very low LDL-C should remain an area of interest and further analysis.

Consistent with their respective previous phase 3 trials, ${ }^{91}$ evolocumab and alirocumab were well tolerated over the duration of their CVOTs (median 2.2 and 2.8 years, respectively) in high-risk patients with ASCVD or post-ACS (Figures 3 and 4). ${ }^{62,63}$ No significant differences were observed in these trials between active treatment groups and placebo in the overall rates of adverse events (with the exception of injection-site reactions) serious adverse events, or adverse events thought to be related to the study agent and leading to discontinuation of the study regimen. ${ }^{62,63}$

Anti-PCSK9 therapy had favorable effects on ischemic stroke without increasing hemorrhagic stroke. In ODYSSEY OUTCOMES, while targeting LDL-C levels of $25-50 \mathrm{mg} / \mathrm{dL}$ and avoiding levels $<15 \mathrm{mg} / \mathrm{dL}$, over median follow-up of 2.8 years, alirocumab reduced the risk of any stroke, and ischemic stroke, without increasing the risk of hemorrhagic stroke, irrespective of baseline 


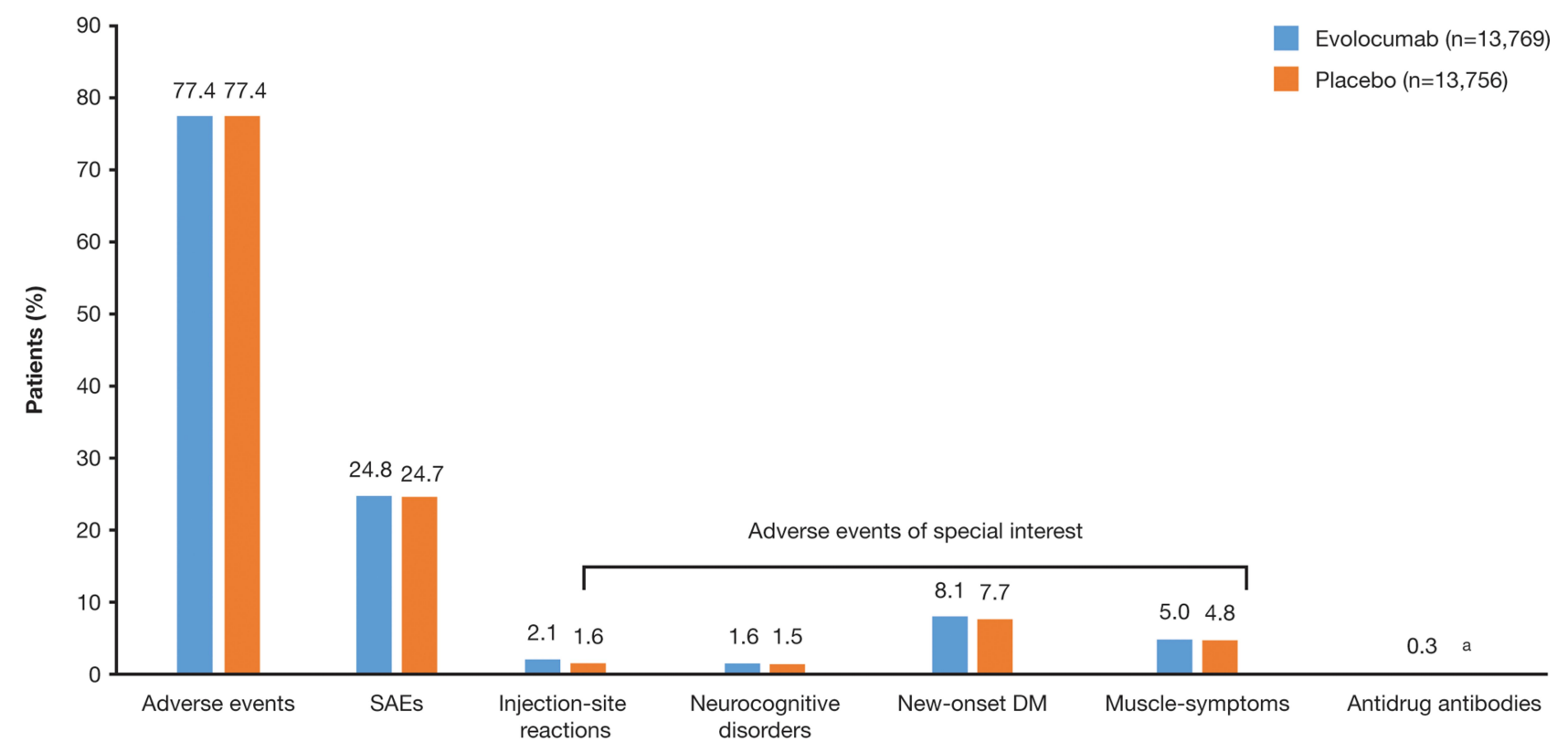

Figure 3 FOURIER ${ }^{63}$ safety summary and antidrug antibody incidence. ${ }^{a}$ Not reported. Abbreviations: DM, diabetes mellitus; SAE, serious adverse event.

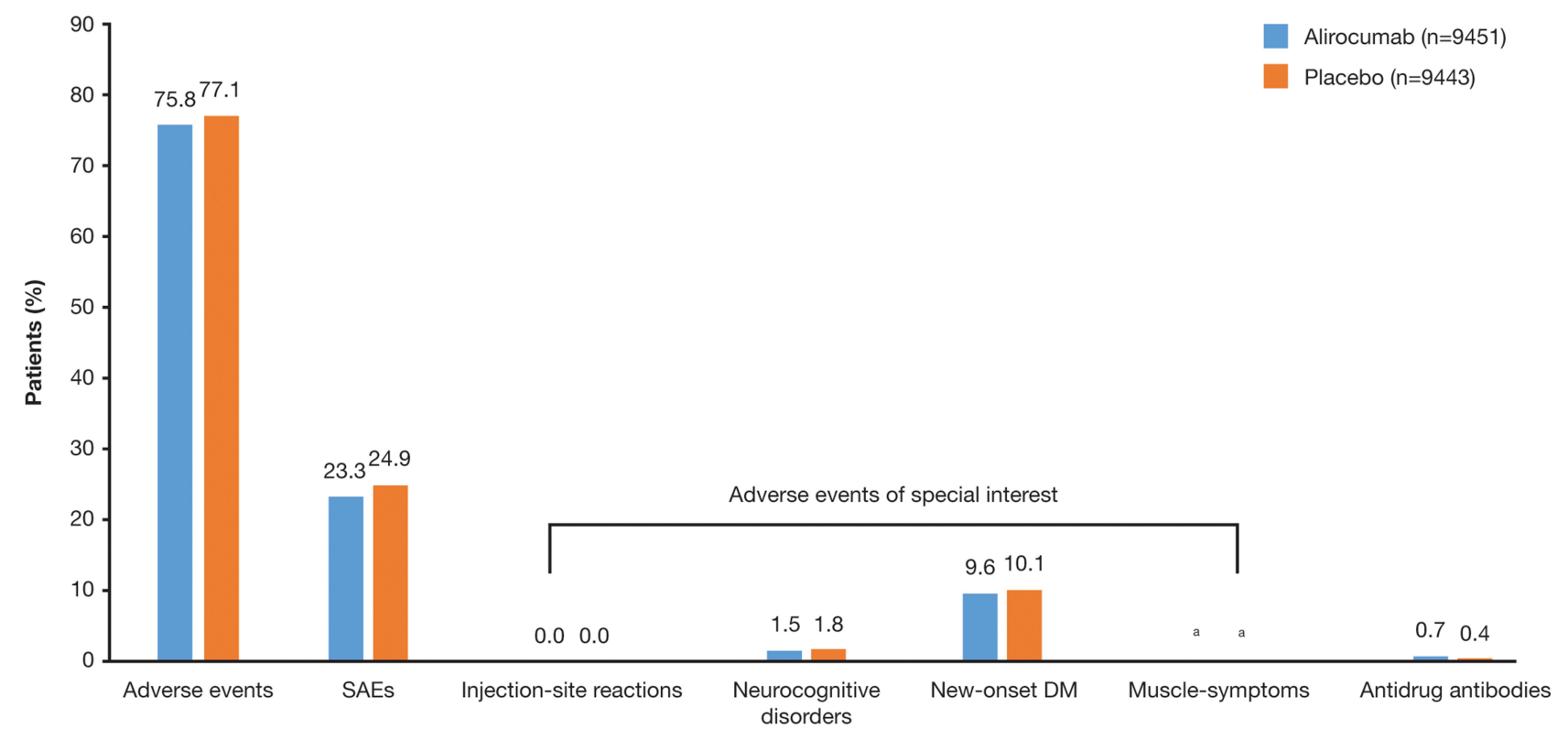

Figure 4 ODYSSEY OUTCOMES ${ }^{62}$ safety summary and antidrug antibody incidence. ${ }^{\text {and }}$ Not reported.

Abbreviations: DM, diabetes mellitus; SAE, serious adverse event.

LDL-C and history of cerebrovascular disease, and the treatment effect appeared numerically greater for patients with higher baseline LDL-C. ${ }^{92}$ A limit on lower achieved LDL-C levels was not applied in FOURIER and, compared with placebo, the rate of hemorrhagic stroke was not increased. $^{63}$

PCSK9 is expressed in low levels in tissues other than the liver (the pancreas, central nervous system, kidney, and intestine). Some authors have speculated that PCSK9 may play a role in other physiological processes beyond LDL-C control such as cell proliferation, but this hypothesis remains unproven. Patients with loss of function PCSK9 mutations have low $\mathrm{CV}$ event rates and do not appear to have an increased risk of non-CV problems. Further, no safety concerns such as increased cancer risk have been observed with PCSK9 inhibition. ${ }^{93}$ Although the longer- 
term safety of PCSK9 mAbs requires observation, to date, in randomized controlled trials of PCSK9 inhibitors vs control, PCSK9 inhibitors and lower achieved LDL-C have no association with "off-target" risk. These analyses have included no findings of increased non-CV serious adverse events, discontinuations due to non-CV adverse events, neurocognitive adverse events, incidence of hemorrhagic stroke, ${ }^{63,92}$ incidence or worsening of preexisting diabetes, ${ }^{70,78}$ muscle-related events, increase in levels of alanine or aspartate aminotransferase, creatine kinase increases, or myalgia. ${ }^{94,95}$

\section{Guideline Recommendations for High/Very High- and Extreme-Risk Patients}

With each revision, cholesterol guidelines have supported lower LDL-C levels in line with the latest data. Over time, these data derived from trials of statins vs placebo, more intensive vs less intensive statin therapy, and now from the PCSK9 CVOTs. The LDL-C goal/threshold recommendations from the 2018 American College of Cardiology/ American Heart Association are $<70 \mathrm{mg} / \mathrm{dL}(1.8 \mathrm{mmol} / \mathrm{L})$ for high- and very high-risk patients, and aggressive lipidlowering therapy is recommended to achieve this. ${ }^{4}$ Additional non-statin therapy with ezetimibe as the initial agent is recommended for very high-risk patients, with a PCSK9 inhibitor on background ezetimibe and maximally tolerated statin therapy when LDL-C remains $\geq 70 \mathrm{mg} / \mathrm{dL}$.

In addition to recommending high-intensity or maximally tolerated statin therapy for secondary prevention in patients with ASCVD, the American College of Cardiology/American Heart Association cholesterol guidelines (Figure 5A) and the European Society of Cardiology (ESC)/European Atherosclerosis Society (EAS) dyslipidemia guidelines (Figure 5B) provide specific recommendations based on high- and very high-risk categories. ${ }^{4,6}$ The American Association of Clinical Endocrinologists/ American College of Endocrinology consensus also endorses combination treatment beyond statins, and describes an additional risk category, extreme risk (ie progressive ASCVD and ASCVD plus additional risk factors) (Figure 5C), with goals of $<55 \mathrm{mg} / \mathrm{dL}(1.4 \mathrm{mmol} / \mathrm{L})$ and $<70 \mathrm{mg} / \mathrm{dL}(1.8 \mathrm{mmol} / \mathrm{L})$ for very high- and high-risk patients, respectively. ${ }^{5}$ The consensus also agrees that ezetimibe may be used before a PCSK9 inhibitor because of its lower price, but for extreme-risk patients for whom LDL-C remains high, immediate progression to PCSK9 inhibitor therapy is recommended. In line with "lower LDL-C is better" for CV prevention, the ESC/EAS dyslipidemia guidelines recommend both at least a $50 \%$ reduction from baseline LDL-C levels, and target LDL-C levels of $<70 \mathrm{mg} / \mathrm{dL}(<1.8 \mathrm{mmol} / \mathrm{L})$ and $<55 \mathrm{mg} / \mathrm{dL}(1.4 \mathrm{mmol} / \mathrm{L})$ for high- and very high-risk patients, respectively. ${ }^{6}$ To attain these low LDL-C levels, combination therapy is recommended, first with ezetimibe then a PCSK9 inhibitor. ${ }^{6}$

Based on the results of $\operatorname{statin}^{96-98}$ and PCSK9 inhibitor CVOTs, ${ }^{62}$ new to the ESC/EAS guidelines is the recognition that patients post recent ACS are at very high risk of recurrent ischemic events. ${ }^{6}$ For post-ACS patients with any recurrent vascular within 2 years despite maximally tolerated statin therapy, a lower target of $<40 \mathrm{mg} / \mathrm{dL}(<1.0 \mathrm{mmol} / \mathrm{L})$ may be considered. ${ }^{6}$ To attain such low levels, combination therapy is recommended, first with ezetimibe then a PCSK9 inhibitor.

\section{Emerging PCSK9-Targeted Therapies for Cardiovascular Risk Reduction}

Subsequent to the discovery of PCSK9 as a target for LDL-C lowering and the development of mAbs to PCSK9, novel therapies in various stages of development have emerged. These new approaches to targeting PCSK9 include small interfering RNA molecules that block the hepatic production of PCSK9, PCSK9 gene silencing with CRISPR-Cas9 gene editing strategies, small molecules that inhibit PCSK9-LDL receptor binding or promote LDL receptor recycling, and PCSK9 vaccines that utilize the patient's immune system to eliminate circulating PCSK9 levels. A review of these therapies in various early stages of development is beyond the scope of this article. Further details of these novel potential therapies can be found elsewhere, as reviewed by Seidah et al $2019 .^{99}$

The most advanced of these potential therapies is inclisiran, a synthetic small interfering RNA that reduces the hepatic production of PCSK9. Inclisiran targets PCSK9 synthesis at the intracellular level of hepatocytes while systemic PCSK9 mAbs target circulating PCSK9 at the extracellular level of hepatocytes to reduce PCSK9 and LDL-C levels. ${ }^{24}$ Hepatocytes are the main source of circulating PCSK9, with a lower expression in the intestine, kidneys, and blood vessels. ${ }^{100}$

Inclisiran markedly reduced LDL-C levels in a 6-month phase 2 trial (ORION 1) ${ }^{101}$ in high-risk patients receiving either statin therapy or ezetimibe, regardless of diabetes ${ }^{102}$ or 
A

Very-high risk
- History of multiple major ASCVD
events
- One major ASCVD event and
multiple high-risk conditions
o Major ASCVD events: recent
ACS (within the past 12 months);
history of MI (other than recent
ACS event listed above); history
of ischemic stroke; symptomatic
PAD (history of claudication with
ABI <0.85 or previous
revascularization or amputation).

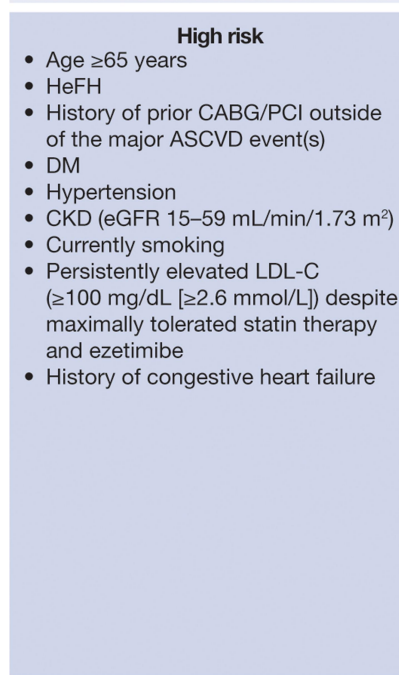

B

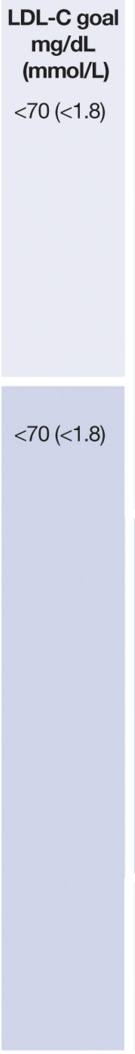

Very-high risk ASCVD, either clinical or unequivocal on imaging ${ }^{\text {a }}$ (ie, previous ACS, stable angina, coronary revascularization, stroke and TIA, and PAD

- DM with target organ damage, $\geq 3$ major risk factors or early onset of type $1 \mathrm{DM}$ of long duration ( $>20$ years)

- Severe CKD (eGFR <30 mL/min/1.73 m²)

- 10-year risk of fatal CVD: calculated SCORE $\geq 10 \%$

- FH with ASCVD or with another major risk factor

- ACS patients who experience a second vascular event within 2 years (not necessarily of the same type as the first event) while taking maximally tolerated stain therapy

\section{High risk}

- Markedly elevated single risk factors, in particular TC $>8 \mathrm{mmol} / \mathrm{L}$ ( $>310 \mathrm{mg} / \mathrm{dL}$ ), LDL-C $>4.9 \mathrm{mmol} / \mathrm{L}$ (>190 mg/dL), or BP $\geq 180 / 110 \mathrm{mmHg}$

- FH without other major risk factors

- DM without target organ damage, ${ }^{*}$ with $\mathrm{DM}$ duration $\geq 10$ years or other additional risk factors

- Moderate CKD (eGFR 30-59 mL/min $\left.11.73 \mathrm{~m}^{2}\right)$

- 10-year risk of fatal CVD: calculated SCORE $>5 \%$ and $<10 \%$

\section{Moderate risk}

- Young patients (type $1 \mathrm{DM}<35$ years: type $2 \mathrm{DM}<50$ years) with DM duration $<10$ years, without other risk factors, 10 -year risk of fatal CVD: calculated SCORE $\geq 1 \%$ and $<5 \%$
C

\begin{tabular}{|c|c|c|}
\hline $\begin{array}{l}\text { LDL-C goal, } \\
\text { mg/dL } \\
(\mathrm{mmol} / \mathrm{L}) \\
<55(<1.4) \\
\text { and } \geq 50 \% \\
\text { reduction } \\
\text { from } \\
\text { baseline }\end{array}$ & $\begin{array}{l}\text { Extreme risk } \\
\text { - Progressive ASCVD including } \\
\text { unstable angina in patients after } \\
\text { achieving an LDL-C }<70 \mathrm{mg} / \mathrm{dL} \\
\text { - Established clinical cardiovascular } \\
\text { disease in patients with DM, CKD } \\
\text { stage } 3 / 4 \text {, or HeFH } \\
\text { - History of premature ASCVD (aged } \\
<55 \text { years male or }<65 \text { years female) }\end{array}$ & $\begin{array}{l}\text { LDL-C goal } \\
\text { mg/dL } \\
(\mathrm{mmol} / \mathrm{L})\end{array}$ \\
\hline$<40(<1.0)$ & $\begin{array}{l}\text { Very-high risk } \\
\text { - Established or recent hospitalization } \\
\text { for ACS, coronary, carotid or } \\
\text { peripheral vascular disease, } \\
10 \text {-year risk }>20 \% \\
\text { - DM or CKD stage } 3 / 4 \text { with } \geq 1 \text { risk } \\
\text { factor } \\
\text { - HeFH }\end{array}$ & $<70(<1.8)$ \\
\hline $\begin{array}{l}<70(<1.8) \\
\text { and } \geq 50 \% \\
\text { reduction }\end{array}$ & $\begin{array}{l}\text { High risk } \\
\text { - } \geq 2 \text { risk factors and } 10 \text {-year risk } \\
10-20 \% \\
\text { - Diabetes or CKD stage } 3 / 4 \text { with no } \\
\text { other risk factors }\end{array}$ & $<100(<2.6)$ \\
\hline baseline & $\begin{array}{c}\text { Moderate risk } \\
\text { - } \leq 2 \text { risk factors and a calculated } \\
10 \text {-year risk }<10 \%\end{array}$ & $<100(<2.6)$ \\
\hline$<100(<2.6)$ & & \\
\hline
\end{tabular}

Figure 5 ASCVD risk categories from (A) the 2018 ACC/AHA cholesterol guidelines, ${ }^{4}$ (B) the 2019 ESC/EAS dyslipidemia guidelines, ${ }^{6}$ and $(\mathbf{C})$ the $2017 \mathrm{AACE} / \mathrm{ACE}$ guidelines. ${ }^{5}$ anequivocally documented ASCVD on imaging includes findings known to be predictive of clinical events, such as significant plaque on coronary angiography or CT scan defined by multivessel coronary disease with 2 major epicardial arteries having $>50 \%$ stenosis.

Abbreviations: AACE, American Association of Clinical Endocrinologists; ABI, ankle-brachial index; ACC, American College of Cardiology; ACE, American College of Endocrinology; ACS, acute coronary syndrome; AHA, American Heart Association; ASCVD, atherosclerotic cardiovascular disease; BP, blood pressure; CABG, coronary artery bypass graft; CKD, chronic kidney disease; DM, diabetes mellitus; eGFR, estimated glomerular filtration rate; EAS, European Atherosclerosis Society; ESC, European Society of Cardiology; FH, familial hypercholesterolemia; HeFH, heterozygous familial hypercholesterolemia; LDL-C, low-density lipoprotein cholesterol; MI, myocardial infarction; PAD, peripheral arterial disease; PCI, percutaneous coronary intervention; SCORE, Systematic Coronary Risk Estimation; TC, total cholesterol; TIA, transient ischemic attack.

renal impairment ${ }^{103}$ status. In a prespecified analysis of this trial, LDL-C reductions were maintained at 1-year follow up. ${ }^{104}$ A phase 3 program of three placebo-controlled trials of subcutaneous inclisiran injections dosed twice yearly on background maximum tolerated statin therapy, ORION-9 (NCT03397121), ORION-10 (NCT03399370), and ORION-11 (NCT03400800), was completed late in 2019, and regulatory submission was filed with the United States Food and Drug Administration. In patients with heterozygous familial hypercholesterolemia (ORION-9 ${ }^{105}$ ), ASCVD (ORION-10 ${ }^{106}$ ), and ASCVD or ASCVD risk equivalents (ORION-11 ${ }^{106}$ ), compared with placebo, inclisiran significantly reduced LDL-C up to 17 months by $48 \%, 54 \%$, and $49 \%$, respectively $(\mathrm{p}<0.001$ for all). The safety profile of inclisiran was similar to that of placebo, with no treatmentrelated liver or renal abnormalities, ${ }^{105,106}$ although generally mild injection-site adverse events were more frequent with inclisiran than with placebo. ${ }^{106}$ The ongoing large $(n=15,000$ planned) ORION-4 trial in patients with pre-existing ASCVD will determine whether the marked LDL-C reductions shown in these trials will translate to a reduction in $\mathrm{CV}$ disease risk (Table 1) (NCT03705234). Primary results from this study, which commenced in October 2018, are expected in December 2024.

In the future, lipid-lowering therapies with less frequent dosing regimens due to longer half-lives, or more frequent dosing of therapies with shorter half-lives, may provide favorable uninterrupted $\mathrm{LDL}-\mathrm{C}$ reduction for $\mathrm{CV}$ risk reduction. Additionally, early initiation of LDL-C-lowering therapy with less intensive treatment over a longer duration may provide $\mathrm{CV}$ benefits. A trial of evolocumab in patients without prior MI or stroke is underway (NCT03872401). 
Emerging evidence and new risk stratification strategies may see future cholesterol guideline updates place emphasis on early primary prevention to further reduce $\mathrm{CV}$ risk. Lifelong exposure to LDL-C has been shown to cumulatively increase ASCVD risk, ${ }^{107}$ and early LDL-C lowering, even from childhood, may mitigate this risk. ${ }^{108}$ Ideally, high-risk asymptomatic patients should receive lipid-lowering therapy before atherosclerotic plaque development. Polygenic risk scores for coronary artery disease have been shown to identify higher-risk individuals, independently of baseline LDL$\mathrm{C}$ and other known risk factors, who may derive greater clinical benefit from statin and/or PCSK9 inhibitors. ${ }^{109,110}$ In post-ACS and ASCVD patients, a high polygenic risk score for coronary artery disease was associated with an elevated risk for recurrent MACE and larger ARR and RRR with alirocumab ${ }^{109}$ and evolocumab, ${ }^{110}$ respectively, providing an independent tool that may be used for risk stratification and early targeted therapy.

\section{Conclusion}

Clinicians treating hypercholesterolemia often encounter patients at high $\mathrm{CV}$ risk despite the appropriate use of maximally tolerated statin therapy. Results from the large FOURIER and ODYSSEY OUTCOMES CVOTs showed that, in high CV risk patients or in patients with recent ACS, the PCSK9 inhibitors evolocumab and alirocumab achieved additional LDL-C and CV risk reduction beyond that seen with statins. ${ }^{62,63}$ Additionally, these results informed the risk categorization and lower LDL-C goals of subsequent cholesterol guideline updates, and those of the 2019 American Association of Clinical Endocrinologists/ American College of Endocrinology consensus statement for the comprehensive management of individuals with type 2 diabetes. ${ }^{4-6,111}$

Subgroup analyses of FOURIER and ODYSSEY OUTCOMES in patients with concurrent PAD, diabetes, or recent MI showed that these patients are at the highest risk of MACE and mortality. ${ }^{68-70,77-79}$ Treatment with alirocumab or evolocumab on background statin therapy resulted in larger ARRs in these high-risk subgroups and lower NNT values (Figure 6), identifying them as those who would derive the greatest benefit from treatment with a PCSK9 mAb.

Uncontrolled elevated LDL-C levels place patients at cumulative increased CV risk. Low/extremely low LDL-C levels are increasingly recognized as ideal. Importantly, the safety and tolerability profiles of alirocumab and evolocumab for LDL-C and CV risk reduction, even down to very low levels, have not raised significant concerns regarding neurocognitive adverse events, diabetes, stroke or cancer risk, muscle-related events, liver dysfunction, or myalgia. ${ }^{62,63,92,94,95}$

PCSK9 inhibitor CVOT results show that optimal therapeutic strategies for secondary prevention should deploy additional aggressive LDL-C-lowering measures to minimize the contribution of hypercholesterolemia to $\mathrm{CV}$ risk in the management of very high/high-risk patients in the clinical setting who may benefit the most. Although access costs and cost-effectiveness have limited recommendations for the use of PCSK9
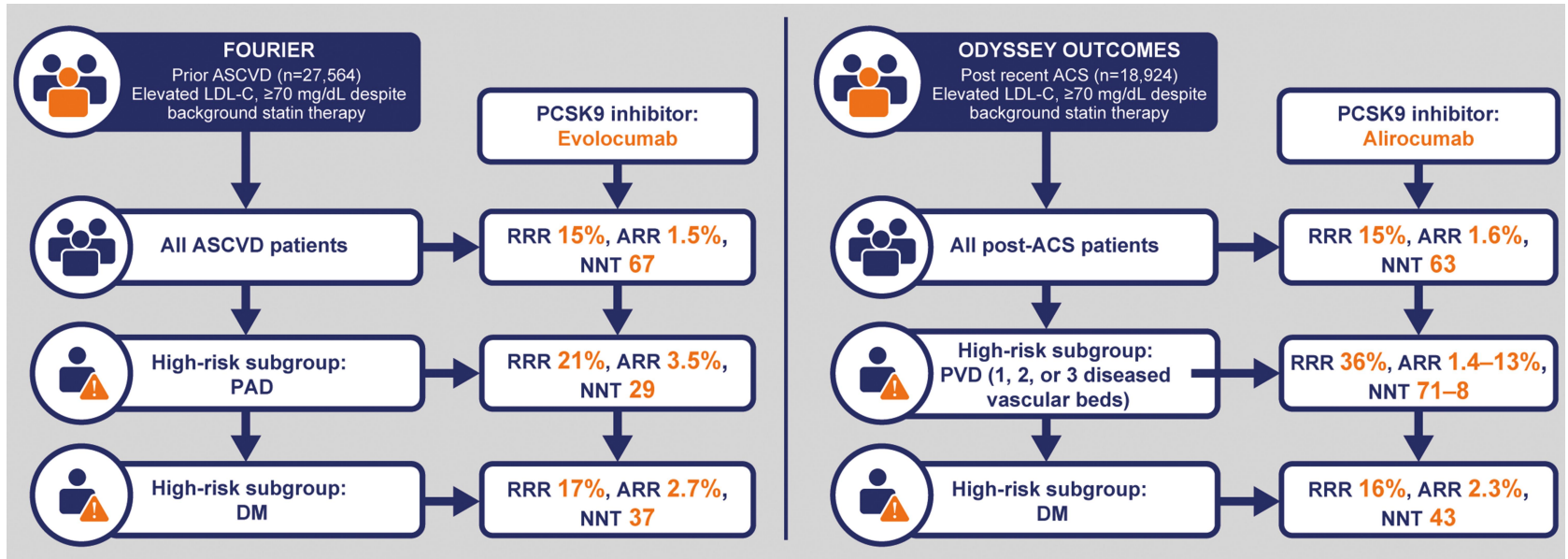

Figure 6 Cardiovascular outcomes trials of PCSK9 inhibitors ${ }^{62,63}$ and benefit in high-risk subgroups. ${ }^{69,70,77,78}$

Abbreviations: ACS, acute coronary syndrome; ARR, absolute risk reduction; ASCVD, atherosclerotic cardiovascular disease; DM, diabetes mellitus, LDL-C, low-density lipoprotein cholesterol; PAD, peripheral arterial disease; PVD, polyvascular disease; RRR, relative risk reduction. 
inhibitors in the past, the subsequent price reductions and the identification of patients most likely to benefit from PSCK9 inhibitor therapy may impact future prospects for $\mathrm{CV}$ risk reduction in the clinical setting.

\section{Acknowledgments}

Medical writing assistance and editorial support, under the direction of the authors, was provided by Nila Bhana, MSc, and Rob Campbell, PhD, of Prime, Knutsford, UK, funded by Sanofi and Regeneron Pharmaceuticals, Inc., according to Good Publication Practice guidelines (https://www.acp journals.org/doi/10.7326/M15-0288).

\section{Author Contributions}

All authors made substantial contributions to conception and design, acquisition of data, or analysis and interpretation of data; took part in drafting the article or revising it critically for important intellectual content; agreed to submit to the current journal; gave final approval of the version to be published; and agree to be accountable for all aspects of the work. Authors received no honoraria related to the development of this publication.

\section{Funding}

This study was funded by Sanofi and Regeneron Pharmaceuticals, Inc.

\section{Disclosure}

Employees of Sanofi and Regeneron Pharmaceuticals, Inc., were permitted to review the manuscript and offer comments. However, the authors were responsible for all content and editorial decisions. Dr Duprez has received clinical trial support from Regeneron Pharmaceuticals, Inc., AstraZeneca, and Esperion. Dr Handelsman has received research grants, and consultant and speaker honoraria from Amarin, Amgen, Applied Therapeutic, AstraZeneca, Bristol-Myers Squibb, Boehringer Ingelheim, Boehringer IngelheimEli Lilly and Company alliance, Esperion, Gan \& Lee, Gilead, Janssen, Merck, Mylan, Merck-Pfizer, Novo Nordisk A/S, and Sanofi; and reports non-financial support from Sanofi, during the conduct of the study; grants and personal fees from Amgen and Novo, grants, personal fees, and non-financial support from Astrazeneca and Sanofi, and personal fees from Esperion and Regeneron Pharmaceuticals, Inc., outside the submitted work. Dr Koren is an employee of a company that has received study grants and consulting fees from manufacturers of PCSK9 inhibitors and treatments for lipid disorders. The authors report no other potential conflicts of interest for this work.

\section{References}

1. Benjamin EJ, Muntner P, Alonso A, et al. Heart disease and stroke statistics-2019 update: a report from the American Heart Association. Circulation. 2019;139(10):e56-e528. doi:10.1161/CIR.0000000000000659

2. Joseph P, Leong D, McKee M, et al. Reducing the global burden of cardiovascular disease, Part 1: the epidemiology and risk factors. Circ Res. 2017;121(6):677-694. doi:10.1161/ CIRCRESAHA.117.308903

3. Ference BA, Ginsberg HN, Graham I, et al. Low-density lipoproteins cause atherosclerotic cardiovascular disease. 1. Evidence from genetic, epidemiologic, and clinical studies. A consensus statement from the European Atherosclerosis Society Consensus Panel. Eur Heart J. 2017;38(32):2459-2472. doi:10.1093/eurheartj/ehx144

4. Grundy SM, Stone NJ, Bailey AL, et al. 2018 AHA/ACC/ AACVPR/AAPA/ABC/ACPM/ADA/AGS/APhA/ASPC/NLA/ PCNA Guideline on the Management of Blood Cholesterol: executive Summary: a report of the american college of cardiology/american heart association task force on clinical practice guidelines. $J$ Am Coll Cardiol. 2019;73(24):3168-3209. doi:10.1016/j.jacc.2018.11.002

5. Jellinger PS, Handelsman Y, Rosenblit PD, et al. American Association of Clinical Endocrinologists and American College of Endocrinology guidelines for management of dyslipidemia and prevention of cardiovascular disease. Endocr Pract. 2017;23 (Suppl 2):1-87. doi:10.4158/ep171764.appgl

6. Mach F, Baigent C, Catapano AL, et al. 2019 ESC/EAS Guidelines for the management of dyslipidaemias: lipid modification to reduce cardiovascular risk. Eur Heart J. 2019. https:// www.ncbi.nlm.nih.gov/pubmed/31504418.

7. Cholesterol Treatment Trialists Collaboration. Efficacy and safety of statin therapy in older people: a meta-analysis of individual participant data from 28 randomised controlled trials. Lancet. 2019;393(10170):407-415. doi:10.1016/S0140-6736(18)31942-1.

8. Newman CB, Preiss D, Tobert JA, et al. Statin safety and associated adverse events: a scientific statement from the american heart association. Arterioscler Thromb Vasc Biol. 2019;39(2): e38-e81. doi:10.1161/atv.0000000000000073

9. Jones PH, Nair R, Thakker KM. Prevalence of dyslipidemia and lipid goal attainment in statin-treated subjects from 3 data sources: a retrospective analysis. $J$ Am Heart Assoc. 2012;1(6): e001800. doi:10.1161/JAHA.112.001800

10. Ridker PM, Mora S, Rose L, Jupiter Trial Study Group. Percent reduction in LDL cholesterol following high-intensity statin therapy: potential implications for guidelines and for the prescription of emerging lipid-lowering agents. Eur Heart J. 2016;37 (17):1373-1379. doi:10.1093/eurheartj/ehw046

11. Adhyaru BB, Jacobson TA. Safety and efficacy of statin therapy. Nat Rev Cardiol. 2018;15(12):757-769. doi:10.1038/s41569-0180098-5

12. Toth PP, Patti AM, Giglio RV, et al. Management of statin intolerance in 2018: still more questions than answers. $\mathrm{Am}$ J Cardiovasc Drugs. 2018;18(3):157-173. doi:10.1007/s40256017-0259-7

13. Pedro-Botet J, Climent E, Benaiges D. Muscle and statins: from toxicity to the nocebo effect. Expert Opin Drug Saf. 2019;18 (7):573-579. doi:10.1080/14740338.2019.1615053 
14. Zhang H, Plutzky J, Turchin A. Discontinuation of statins in routine care settings. Ann Intern Med. 2013;159(1):75-76. doi:10.7326/0003-4819-159-1-201307020-00022

15. Ridker PM, Danielson E, Fonseca FA, et al. Rosuvastatin to prevent vascular events in men and women with elevated C-reactive protein. $N$ Engl J Med. 2008;359(21):2195-2207. doi:10.1056/NEJMoa0807646

16. Sattar N, Preiss D, Murray HM, et al. Statins and risk of incident diabetes: a collaborative meta-analysis of randomised statin trials. Lancet. 2010;375(9716):735-742. doi:10.1016/S0140-6736(09) 61965-6

17. Thakker D, Nair S, Pagada A, Jamdade V, Malik A. Statin use and the risk of developing diabetes: a network meta-analysis. Pharmacoepidemiol Drug Saf. 2016;25(10):1131-1149. doi:10.1002/pds. 4020

18. Cannon CP, Blazing MA, Giugliano RP, et al. Ezetimibe added to statin therapy after acute coronary syndromes. $N$ Engl $J$ Med. 2015;372(25):2387-2397. doi:10.1056/NEJMoa1410489

19. Jakob T, Nordmann AJ, Schandelmaier S, Ferreira-Gonzalez I, Briel M. Fibrates for primary prevention of cardiovascular disease events. Cochrane Database Syst Rev. 2016;11:CD009753. doi:10.1002/14651858.CD009753.pub2

20. Schandelmaier S, Briel M, Saccilotto R, et al. Niacin for primary and secondary prevention of cardiovascular events. Cochrane Database Syst Rev. 2017;6:CD009744. doi:10.1002/14651858. CD009744

21. Seidah NG, Benjannet $\mathrm{S}$, Wickham $\mathrm{L}$, et al. The secretory proprotein convertase neural apoptosis-regulated convertase 1 (NARC-1): liver regeneration and neuronal differentiation. Proc Natl Acad Sci U S A. 2003;100(3):928-933. doi:10.1073/ pnas. 0335507100

22. Cohen JC, Boerwinkle E, Mosley TH Jr., Hobbs HH. Sequence variations in PCSK9, low LDL, and protection against coronary heart disease. $N$ Engl $J$ Med. 2006;354(12):1264-1272. doi:10.1056/NEJMoa054013

23. Seidah NG, Awan Z, Chretien M, Mbikay M. PCSK9: a key modulator of cardiovascular health. Circ Res. 2014;114 (6):1022-1036. doi:10.1161/circresaha.114.301621

24. Lambert G, Sjouke B, Choque B, Kastelein JJ, Hovingh GK. The PCSK9 decade. $J$ Lipid Res. 2012;53(12):2515-2524. doi:10.1194/jlr.R026658

25. Ballantyne CM, Neutel J, Cropp A, et al. Results of bococizumab, a monoclonal antibody against proprotein convertase subtilisin/ kexin type 9, from a randomized, placebo-controlled, dose-ranging study in statin-treated subjects with hypercholesterolemia. Am J Cardiol. 2015;115(9):1212-1221. doi:10.1016/j.amjcard.2015.02.006

26. Ridker PM, Revkin J, Amarenco P, et al. Cardiovascular efficacy and safety of bococizumab in high-risk patients. $N$ Engl J Med. 2017;376(16):1527-1539. doi:10.1056/NEJMoa1701488

27. Giugliano RP, Desai NR, Kohli P, et al. Efficacy, safety, and tolerability of a monoclonal antibody to proprotein convertase subtilisin/ kexin type 9 in combination with a statin in patients with hypercholesterolaemia (LAPLACE-TIMI 57): a randomised, placebo-controlled, dose-ranging, phase 2 study. Lancet. 2012;380 (9858):2007-2017. doi:10.1016/S0140-6736(12)61770-X

28. McKenney JM, Koren MJ, Kereiakes DJ, et al. Safety and efficacy of a monoclonal antibody to proprotein convertase subtilisin/ kexin type 9 serine protease, SAR236553/REGN727, in patients with primary hypercholesterolemia receiving ongoing stable atorvastatin therapy. J Am Coll Cardiol. 2012;59(25):2344-2353. doi:10.1016/j.jacc.2012.03.007

29. Roth EM, McKenney JM, Hanotin C, Asset G, Stein EA. Atorvastatin with or without an antibody to PCSK9 in primary hypercholesterolemia. $N$ Engl J Med. 2012;367(20):1891-1900. doi:10.1056/NEJMoa1201832
30. Stein EA, Gipe D, Bergeron J, et al. Effect of a monoclonal antibody to PCSK9, REGN727/SAR236553, to reduce low-density lipoprotein cholesterol in patients with heterozygous familial hypercholesterolaemia on stable statin dose with or without ezetimibe therapy: a phase 2 randomised controlled trial. Lancet. 2012;380(9836):29-36. doi:10.1016/S0140-6736(12)60771-5

31. Stein EA, Mellis S, Yancopoulos GD, et al. Effect of a monoclonal antibody to PCSK9 on LDL cholesterol. $N$ Engl $J$ Med. 2012;366(12):1108-1118. doi:10.1056/NEJMoa1105803

32. Koren MJ, Scott R, Kim JB, et al. Efficacy, safety, and tolerability of a monoclonal antibody to proprotein convertase subtilisin/ kexin type 9 as monotherapy in patients with hypercholesterolaemia (MENDEL): a randomised, double-blind, placebo-controlled, phase 2 study. Lancet. 2012;380(9858):1995-2006. doi:10.1016/ s0140-6736(12)61771-1

33. Roth EM, Taskinen MR, Ginsberg HN, et al. Monotherapy with the PCSK9 inhibitor alirocumab versus ezetimibe in patients with hypercholesterolemia: results of a 24 week, double-blind, randomized Phase 3 trial. Int $J$ Cardiol. 2014;176(1):55-61. doi:10.1016/j.ijcard.2014.06.049

34. Cannon CP, Cariou B, Blom D, et al. Efficacy and safety of alirocumab in high cardiovascular risk patients with inadequately controlled hypercholesterolaemia on maximally tolerated doses of statins: the ODYSSEY COMBO II randomized controlled trial. Eur Heart J. 2015;36(19):1186-1194. doi:10.1093/eurheartj/ehv028

35. Kastelein JJ, Ginsberg HN, Langslet G, et al. ODYSSEY FH I and FH II: 78 week results with alirocumab treatment in 735 patients with heterozygous familial hypercholesterolaemia. Eur Heart J. 2015;36(43):2996-3003. doi:10.1093/eurheartj/ehv370

36. Navarese EP, Kolodziejczak M, Schulze V, et al. Effects of proprotein convertase subtilisin/kexin type 9 antibodies in adults with hypercholesterolemia: a systematic review and meta-analysis. Ann Intern Med. 2015;163(1):40-51. doi:10.7326/M14-2957

37. Raal FJ, Honarpour N, Blom DJ, et al. Inhibition of PCSK9 with evolocumab in homozygous familial hypercholesterolaemia (TESLA Part B): a randomised, double-blind, placebo-controlled trial. Lancet. 2015;385(9965):341-350. doi:10.1016/S01406736(14)61374-X

38. Raal FJ, Stein EA, Dufour R, et al. PCSK9 inhibition with evolocumab (AMG 145) in heterozygous familial hypercholesterolaemia (RUTHERFORD-2): a randomised, double-blind, placebo-controlled trial. Lancet. 2015;385(9965):331-340. doi:10.1016/s0140-6736(14)61399-4

39. Robinson JG, Nedergaard BS, Rogers WJ, et al. Effect of evolocumab or ezetimibe added to moderate- or high-intensity statin therapy on LDL-C lowering in patients with hypercholesterolemia: the LAPLACE-2 randomized clinical trial. JAMA. 2014;311 (18):1870-1882. doi:10.1001/jama.2014.4030

40. Stroes E, Colquhoun D, Sullivan D, et al. Anti-PCSK9 antibody effectively lowers cholesterol in patients with statin intolerance: the GAUSS-2 randomized, placebo-controlled phase 3 clinical trial of evolocumab. $J$ Am Coll Cardiol. 2014;63 (23):2541-2548. doi:10.1016/j.jacc.2014.03.019

41. Kastelein JJ, Hovingh GK, Langslet G, et al. Efficacy and safety of the proprotein convertase subtilisin/kexin type 9 monoclonal antibody alirocumab vs placebo in patients with heterozygous familial hypercholesterolemia. J Clin Lipidol. 2017;11(1):195203e4. doi:10.1016/j.jacl.2016.12.004

42. Hovingh GK, Raal FJ, Dent R, et al. Long-term safety, tolerability, and efficacy of evolocumab in patients with heterozygous familial hypercholesterolemia. $J$ Clin Lipidol. 2017;11 (6):1448-1457. doi:10.1016/j.jacl.2017.09.003

43. Ginsberg HN, Tuomilehto J, Hovingh GK, et al. Impact of age on the efficacy and safety of alirocumab in patients with heterozygous familial hypercholesterolemia. Cardiovasc Drugs Ther. 2019;33(1):69-76. doi:10.1007/s10557-019-06852-6 
44. Harvey PD, Sabbagh MN, Harrison JE, et al. No evidence of neurocognitive adverse events associated with alirocumab treatment in 3340 patients from 14 randomized Phase 2 and 3 controlled trials: a meta-analysis of individual patient data. Eur Heart J. 2018;39(5):374-381. doi:10.1093/eurheartj/ehx661

45. Koren MJ, Lundqvist $P$, Bolognese $M$, et al. Anti-PCSK9 monotherapy for hypercholesterolemia: the MENDEL-2 randomized, controlled Phase III clinical trial of evolocumab. $J$ Am Coll Cardiol. 2014;63(23):2531-2540. doi:10.1016/j. jacc.2014.03.018

46. Moriarty PM, Thompson PD, Cannon CP, et al. Efficacy and safety of alirocumab vs ezetimibe in statin-intolerant patients, with a statin rechallenge arm: the ODYSSEY ALTERNATIVE randomized trial. J Clin Lipidol. 2015;9(6):758-769. doi:10.1016/ j.jacl.2015.08.006

47. Leiter LA, Tinahones FJ, Karalis DG, et al. Alirocumab safety in people with and without diabetes mellitus: pooled data from 14 ODYSSEY trials. Diabet Med. 2018;35(12):1742-1751. doi:10.1111/dme.13817

48. Ginsberg HN, Farnier M, Robinson JG, et al. Efficacy and safety of alirocumab in individuals with diabetes mellitus: pooled analyses from five placebo-controlled Phase 3 studies. Diabetes Ther. 2018;9(3):1317-1334. doi:10.1007/s13300-0180439-8

49. Sattar N, Preiss D, Robinson JG, et al. Lipid-lowering efficacy of the PCSK9 inhibitor evolocumab (AMG 145) in patients with type 2 diabetes: a meta-analysis of individual patient data. Lancet Diabetes Endocrinol. 2016;4(5):403-410. doi:10.1016/S22138587(16)00003-6

50. Leiter LA, Cariou B, Muller-Wieland D, et al. Efficacy and safety of alirocumab in insulin-treated individuals with type 1 or type 2 diabetes and high cardiovascular risk: the ODYSSEY DM-INSULIN randomized trial. Diabetes Obes Metab. 2017;19 (12):1781-1792. doi:10.1111/dom.13114

51. Ray KK, Leiter LA, Muller-Wieland D, et al. Alirocumab vs usual lipid-lowering care as add-on to statin therapy in individuals with type 2 diabetes and mixed dyslipidaemia: the ODYSSEY DM-DYSLIPIDEMIA randomized trial. Diabetes Obes Metab. 2018;20(6):1479-1489. doi:10.1111/dom.13257

52. Rosenson RS, Jacobson TA, Preiss D, et al. Efficacy and safety of the PCSK9 inhibitor evolocumab in patients with mixed hyperlipidemia. Cardiovasc Drugs Ther. 2016;30(3):305-313. doi:10.1007/s10557-016-6666-1

53. Taskinen MR, Del Prato S, Bujas-Bobanovic M, et al. Efficacy and safety of alirocumab in individuals with type 2 diabetes mellitus with or without mixed dyslipidaemia: analysis of the ODYSSEY LONG TERM trial. Atherosclerosis. 2018;276:124-130. doi:10.1016/j.atherosclerosis.2018.07.017

54. Charytan DM, Sabatine MS Efficacy and Safety of Evolocumab in CKD: data from the FOURIER Trial. American Society of Nephrology Annual Conference, San Diego, CA; 2018.

55. Toth PP, Dwyer JP, Cannon CP, et al. Efficacy and safety of lipid lowering by alirocumab in chronic kidney disease. Kidney Int. 2018;93(6):1397-1408. doi:10.1016/j.kint.2017.12.011

56. Ganda OP, Plutzky J, Sanganalmath SK, et al. Efficacy and safety of alirocumab among individuals with diabetes mellitus and atherosclerotic cardiovascular disease in the ODYSSEY phase 3 trials. Diabetes Obes Metab. 2018;20(10):2389-2398. doi:10.1111/ dom. 13384

57. McCullough PA, Ballantyne CM, Sanganalmath SK, et al. Efficacy and safety of alirocumab in high-risk patients with clinical atherosclerotic cardiovascular disease and/or heterozygous familial hypercholesterolemia (From 5 placebo-controlled ODYSSEY trials). Am J Cardiol. 2018;121(8):940-948. doi:10.1016/j.amjcard.2017.12.040
58. Kereiakes DJ, Lepor NE, Gerber R, et al. Efficacy and safety of alirocumab in patients with or without prior coronary revascularization: pooled analysis of eight ODYSSEY phase 3 trials. Atherosclerosis. 2018;277:211-218. doi:10.1016/j.atherosclerosis. 2018.07.010

59. Ray KK, Del Prato S, Muller-Wieland D, et al. Alirocumab therapy in individuals with type 2 diabetes mellitus and atherosclerotic cardiovascular disease: analysis of the ODYSSEY DM-DYSLIPIDEMIA and DM-INSULIN studies. Cardiovasc Diabetol. 2019;18(1):149. doi:10.1186/s12933-019-0951-9

60. Robinson JG, Farnier M, Krempf M, et al. Efficacy and safety of alirocumab in reducing lipids and cardiovascular events. $N$ Engl J Med. 2015;372(16):1489-1499. doi:10.1056/NEJMoa1501031

61. Sabatine MS, Giugliano RP, Wiviott SD, et al. Efficacy and safety of evolocumab in reducing lipids and cardiovascular events. N Engl J Med. 2015;372(16):1500-1509. doi:10.1056/ NEJMoa1500858

62. Schwartz GG, Steg PG, Szarek M, et al. Alirocumab and cardiovascular outcomes after acute coronary syndrome. $N$ Engl $J$ Med. 2018;379(22):2097-2107. doi:10.1056/NEJMoa1801174

63. Sabatine MS, Giugliano RP, Keech AC, et al. Evolocumab and clinical outcomes in patients with cardiovascular disease. $N$ Engl $J$ Med. 2017;376(18):1713-1722. doi:10.1056/NEJMoa1615664

64. Gaudet D, Watts GF, Robinson JG, et al. Effect of alirocumab on lipoprotein(a) over $\geq 1.5$ years (from the Phase 3 ODYSSEY Program). Am J Cardiol. 2017;119(1):40-46. doi:10.1016/j. amjcard.2016.09.010

65. Raal FJ, Giugliano RP, Sabatine MS, et al. Reduction in lipoprotein(a) with PCSK9 monoclonal antibody evolocumab (AMG 145): a pooled analysis of more than 1300 patients in 4 Phase II trials. J Am Coll Cardiol. 2014;63(13):1278-1288. doi:10.1016/j.jacc.2014.01.006

66. Ray KK, Vallejo-Vaz AJ, Ginsberg HN, et al. Lipoprotein(a) reductions from PCSK9 inhibition and major adverse cardiovascular events: pooled analysis of alirocumab phase 3 trials. Atherosclerosis. 2019;288:194-202. doi:10.1016/j. atherosclerosis.2019.06.896

67. O'Donoghue ML, Fazio S, Giugliano RP, et al. Lipoprotein(a), PCSK9 inhibition, and cardiovascular risk. Circulation. 2019;139 (12):1483-1492. doi:10.1161/CIRCULATIONAHA.118.037184

68. Murphy SA, Pedersen TR, Gaciong ZA, et al. Effect of the PCSK9 inhibitor evolocumab on total cardiovascular events in patients with cardiovascular disease: a prespecified analysis from the FOURIER trial. JAMA Cardiol. 2019;4(7):613-619. doi:10.1001/jamacardio.2019.0886

69. Bonaca MP, Nault P, Giugliano RP, et al. Low-density lipoprotein cholesterol lowering with evolocumab and outcomes in patients with peripheral artery disease: insights from the FOURIER trial (Further cardiovascular outcomes research with PCSK9 inhibition in subjects with elevated risk). Circulation. 2018;137(4):338-350. doi:10.1161/CIRCULATIONAHA.117.032235

70. Sabatine MS, Leiter LA, Wiviott SD, et al. Cardiovascular safety and efficacy of the PCSK9 inhibitor evolocumab in patients with and without diabetes and the effect of evolocumab on glycaemia and risk of new-onset diabetes: a prespecified analysis of the FOURIER randomised controlled trial. Lancet Diabetes Endocrinol. 2017;5 (12):941-950. doi:10.1016/S2213-8587(17)30313-3

71. Sabatine MS, De Ferrari GM, Giugliano RP, et al. Clinical benefit of evolocumab by severity and extent of coronary artery disease. Circulation. 2018;138(8):756-766. doi:10.1161/CIRCULATION AHA.118.034309

72. Bays HE. Alirocumab, decreased mortality, nominal significance, $P$ values, Bayesian statistics, and the duplicity of multiplicity. Circulation. 2019;140(2):113-116. doi:10.1161/CIRCULATION AHA.119.041496 
73. Steg PG, Szarek M, Bhatt DL, et al. Effect of alirocumab on mortality after acute coronary syndromes. Circulation. 2019;140 (2):103-112. doi:10.1161/CIRCULATIONAHA.118.038840

74. Szarek M, White HD, Schwartz GG, et al. Alirocumab reduces total nonfatal cardiovascular and fatal events: the ODYSSEY OUTCOMES trial. J Am Coll Cardiol. 2019;73(4):387-396. doi:10.1016/j.jacc.2018.10.039

75. Bittner VA, Szarek M, Aylward PE, et al. Effect of alirocumab on lipoprotein(a) and cardiovascular risk after acute coronary syndrome. J Am Coll Cardiol. 2020;75(2):133-144. doi:10. 1016/j.jacc.2019.10.057

76. Goodman SG, Aylward PE, Szarek M, et al. Effects of alirocumab on cardiovascular events after coronary bypass surgery. J Am Coll Cardiol. 2019;74(9):1177-1186. doi:10.1016/j.jacc.2019.07.015

77. Jukema JW, Szarek M, Zijlstra LE, et al. Alirocumab in patients with polyvascular disease and recent acute coronary syndrome: ODYSSEY OUTCOMES trial. J Am Coll Cardiol. 2019;74 (9):1167-1176. doi:10.1016/j.jacc.2019.03.013

78. Ray KK, Colhoun HM, Szarek M, et al. Effects of alirocumab on cardiovascular and metabolic outcomes after acute coronary syndrome in patients with or without diabetes: a prespecified analysis of the ODYSSEY OUTCOMES randomised controlled trial. Lancet Diabetes Endocrinol. 2019;7(8):618-628. doi:10.1016/ S2213-8587(19)30158-5

79. Sinnaeve PR, Schwartz GG, Wojdyla DM, et al. Effect of alirocumab on cardiovascular outcomes after acute coronary syndromes according to age: an ODYSSEY OUTCOMES trial analysis. Eur Heart J. 2019. doi:10.1093/eurheartj/ehz809

80. Kazi DS, Moran AE, Coxson PG, et al. Cost-effectiveness of PCSK9 inhibitor therapy in patients with heterozygous familial hypercholesterolemia or atherosclerotic cardiovascular disease. JAMA. 2016;316(7):743-753. doi:10.1001/jama.2016.11004

81. Navar AM, Taylor B, Mulder H, et al. Association of prior authorization and out-of-pocket costs with patient access to PCSK9 inhibitor therapy. JAMA Cardiol. 2017;2 (11):1217-1225. doi:10.1001/jamacardio.2017.3451

82. Robinson JG, Jayanna MB, Brown AS, et al. Enhancing the value of PCSK9 monoclonal antibodies by identifying patients most likely to benefit. A consensus statement from the National Lipid Association. J Clin Lipidol. 2019;13(4):525-537. doi:10.1016/j. jacl.2019.05.005

83. Szarek M, Steg PG, DiCenso D, et al. Alirocumab reduces total hospitalizations and increases days alive and out of hospital in the ODYSSEY OUTCOMES trial. Circ Cardiovasc Qual Outcomes. 2019;12(11):e005858. doi:10.1161/circoutcomes.119.005858

84. Bhatt DL, Briggs AH, Reed SD, et al. Cost-effectiveness of alirocumab in patients with acute coronary syndromes: the ODYSSEY OUTCOMES trial. J Am Coll Cardiol. 2020;75 (18):2297-2308. doi:10.1016/j.jacc.2020.03.029

85. Farnier M, Hovingh GK, Langslet G, et al. Long-term safety and efficacy of alirocumab in patients with heterozygous familial hypercholesterolemia: an open-label extension of the ODYSSEY program. Atherosclerosis. 2018;278:307-314. doi:10.1016/j. atherosclerosis.2018.08.036

86. Koren MJ, Giugliano RP, Raal FJ, et al. Efficacy and safety of longer-term administration of evolocumab (AMG 145) in patients with hypercholesterolemia: 52-week results from the Open-Label Study of Long-Term Evaluation Against LDL-C (OSLER) randomized trial. Circulation. 2014;129(2):234-243. doi:10.1161/ CIRCULATIONAHA.113.007012

87. Koren MJ, Sabatine MS, Giugliano RP, et al. Long-term low-density lipoprotein cholesterol-lowering efficacy, persistence, and safety of evolocumab in treatment of hypercholesterolemia: results up to 4 years from the open-label OSLER-1 extension study. JAMA Cardiol. 2017;2(6):598-607. doi:10.1001/jamacardio.2017.0747
88. Koren MJ, Sabatine MS, Giugliano RP, et al. Long-term efficacy and safety of evolocumab in patients with hypercholesterolemia. J Am Coll Cardiol. 2019;74(17):2132-2146. doi:10.1016/j.jacc.2019.08.1024

89. Ray KK, Ginsberg HN, Davidson MH, et al. Reductions in atherogenic lipids and major cardiovascular events: a pooled analysis of 10 ODYSSEY trials comparing alirocumab with control. Circulation. 2016;134(24):1931-1943. doi:10.1161/circulatio naha.116.024604

90. Robinson JG, Rosenson RS, Farnier M, et al. Safety of very low low-density lipoprotein cholesterol levels with alirocumab: pooled data from randomized trials. J Am Coll Cardiol. 2017;69 (5):471-482. doi:10.1016/j.jacc.2016.11.037

91. Jones PH, Bays HE, Chaudhari U, et al. Safety of alirocumab (a PCSK9 monoclonal antibody) from 14 randomized trials. Am J Cardiol. 2016;118(12):1805-1811. doi:10.1016/j.amjcard.2016. 08.072

92. Jukema JW, Zijlstra LE, Bhatt DL, et al. Effect of alirocumab on stroke in ODYSSEY OUTCOMES. Circulation. 2019;140 (25):2054-2062. doi:10.1161/CIRCULATIONAHA.119. 043826

93. Stoekenbroek RM, Lambert G, Cariou B, Hovingh GK. Inhibiting PCSK9 - biology beyond LDL control. Nat Rev Endocrinol. 2018;15(1):52-62. doi:10.1038/s41574-018-0110-5

94. Turgeon RD, Tsuyuki RT, Gyenes GT, Pearson GJ. Cardiovascular efficacy and safety of pcsk9 inhibitors: systematic review and meta-analysis including the ODYSSEY OUTCOMES trial. Can J Cardiol. 2018;34(12):1600-1605. doi:10.1016/j. cjca.2018.04.002

95. Karatasakis A, Danek BA, Karacsonyi J, et al. Effect of PCSK9 inhibitors on clinical outcomes in patients with hypercholesterolemia: a meta-analysis of 35 randomized controlled trials. $J \mathrm{Am}$ Heart Assoc. 2017;6:12. doi:10.1161/JAHA.117.006910

96. Schwartz GG, Olsson AG, Ezekowitz MD, et al. Effects of atorvastatin on early recurrent ischemic events in acute coronary syndromes: the MIRACL study: a randomized controlled trial. JAMA. 2001;285(13):1711-1718. doi:10.1001/jama.285.13.1711

97. de Lemos JA, Blazing MA, Wiviott SD, et al. Early intensive vs a delayed conservative simvastatin strategy in patients with acute coronary syndromes: phase $\mathrm{Z}$ of the A to Z trial. JAMA. 2004;292 (11):1307-1316. doi:10.1001/jama.292.11.1307

98. Cannon $\mathrm{CP}$, Braunwald $\mathrm{E}, \mathrm{McCabe} \mathrm{CH}$, et al. Intensive versus moderate lipid lowering with statins after acute coronary syndromes. $N$ Engl $J$ Med. 2004;350(15):1495-1504. doi:10.1056/NEJMoa040583

99. Seidah NG, Prat A, Pirillo A, Catapano AL, Norata GD. Novel strategies to target proprotein convertase subtilisin kexin 9: beyond monoclonal antibodies. Cardiovasc Res. 2019;115 (3):510-518. doi:10.1093/cvr/cvz003

100. Ferri N, Tibolla G, Pirillo A, et al. Proprotein convertase subtilisin kexin type 9 (PCSK9) secreted by cultured smooth muscle cells reduces macrophages LDLR levels. Atherosclerosis. 2012;220(2):381-386. doi:10.1016/j. atherosclerosis.2011.11.026

101. Ray KK, Landmesser U, Leiter LA, et al. Inclisiran in patients at high cardiovascular risk with elevated LDL cholesterol. $N$ Engl $J$ Med. 2017;376(15):1430-1440. doi:10.1056/NEJMoa1615758

102. Leiter LA, Teoh H, Kallend D, et al. Inclisiran lowers LDL-C and PCSK9 irrespective of diabetes status: the ORION-1 randomized clinical trial. Diabetes Care. 2019;42(1):173-176. doi:10.2337/ dc18-1491

103. Wright RS, Collins MG, Stoekenbroek RM, et al. Effects of renal impairment on the pharmacokinetics, efficacy, and safety of inclisiran: an analysis of the ORION-7 and ORION-1 studies. Mayo Clin Proc. 2020;95(1):77-89. doi:10.1016/j. mayocp.2019.08.021 
104. Ray KK, Stoekenbroek RM, Kallend D, et al. Effect of 1 or 2 doses of inclisiran on low-density lipoprotein cholesterol levels: one-year follow-up of the ORION-1 randomized clinical trial. JAMA Cardiol. 2019;4(11):1067. doi:10.1001/jamacardio.2019.3502

105. Raal FJ, Kallend D, Ray KK, et al. Inclisiran for the treatment of heterozygous familial hypercholesterolemia. $N$ Engl J Med. 2020;382(16):1520-1530. doi:10.1056/NEJMoa1913805

106. Ray KK, Wright RS, Kallend D, et al. Two phase 3 trials of inclisiran in patients with elevated LDL cholesterol. $N$ Engl J Med. 2020;382(16):1507-1519. doi:10.1056/NEJMoa1912387

107. Robinson JG, Gidding SS. Curing atherosclerosis should be the next major cardiovascular prevention goal. J Am Coll Cardiol. 2014;63(25Pt A):2779-2785. doi:10.1016/j.jacc.2014.04.009

108. Luirink IK, Wiegman A, Kusters DM, et al. 20-year follow-up of statins in children with familial hypercholesterolemia. N Engl $J$ Med. 2019;381(16):1547-1556. doi:10.1056/NEJMoa1816454
109. Damask A, Steg PG, Schwartz GG, et al. Patients with high genome-wide polygenic risk scores for coronary artery disease may receive greater clinical benefit from alirocumab treatment in the ODYSSEY OUTCOMES trial. Circulation. 2019. https:// www.ncbi.nlm.nih.gov/pubmed/31707832.

110. Marston NA, Kamanu FK, Nordio F, et al. Predicting benefit from evolocumab therapy in patients with atherosclerotic disease using a genetic risk score: results from the FOURIER trial. Circulation. 2019. https://www.ncbi.nlm.nih.gov/pubmed/31707849.

111. Garber AJ, Abrahamson MJ, Barzilay JI, et al. Consensus statement by the American Association of Clinical Endocrinologists and American College of Endocrinology on the comprehensive type 2 diabetes management algorithm - 2019 executive summary. Endocr Pract. 2019;25(1):69-100. doi:10.4158/cs2018-0535
Vascular Health and Risk Management

\section{Publish your work in this journal}

Vascular Health and Risk Management is an international, peerreviewed journal of therapeutics and risk management, focusing on concise rapid reporting of clinical studies on the processes involved in the maintenance of vascular health; the monitoring, prevention and treatment of vascular disease and its sequelae; and the involvement
Dovepress

of metabolic disorders, particularly diabetes. This journal is indexed on PubMed Central and MedLine. The manuscript management system is completely online and includes a very quick and fair peerreview system, which is all easy to use. Visit http://www.dovepress. com/testimonials.php to read real quotes from published authors. 